\title{
3 Research Square

\section{Monitoring the Damage of Armyworm in Summer Corn by Unmanned Aerial Vehicle Imaging}

mingzheng zhang

China Agricultural University https://orcid.org/0000-0001-7784-7777

\section{Xinsheng Wang}

China Agricultural University

Jinghao Xue

UCL: University College London

Wei Su ( $\square$ suwei@cau.edu.cn )

China Agricultural University https://orcid.org/0000-0002-8726-5858

Dehai Zhu

China Agricultural University

Wancheng Tao

China Agricultural University

\section{Chan Yao}

China Agricultural University

Tian Jin

China Agricultural University

\section{Zixuan Xie}

China Agricultural University

\section{Research}

Keywords: armyworm monitoring, summer corn, Unmanned Aerial Vehicle, Random Forest, Sentinel-2

Posted Date: September 9th, 2020

DOI: https://doi.org/10.21203/rs.3.rs-71451/v1

License: (c) (i) This work is licensed under a Creative Commons Attribution 4.0 International License.

Read Full License 
2 Monitoring the damage of Armyworm in Summer 3 Corn by Unmanned Aerial Vehicle imaging

\author{
4 Mingzheng Zhang ${ }^{1,2}$, Xinsheng Wang ${ }^{1,2}$, Jing-Hao Xue ${ }^{3}$, Wei Su ${ }^{1,2 *}$, Dehai Zhu ${ }^{1,2}$, Wancheng \\ 5 Tao ${ }^{1,2}$, Chan Yao ${ }^{1,2}$, Tian Jin ${ }^{1,2}$, Zixuan Xie ${ }^{1,2}$ \\ 61 College of Land Science and Technology, China Agricultural University, Beijing 100083, China \\ 72 Key Laboratory of Remote Sensing for Agri-Hazards, Ministry of Agriculture, Beijing 100083, China \\ 83 Department of Statistical Science, University College London, London, WC1E 6BT, UK \\ 9 * Correspondence: suwei@cau.edu.cn; Tel.: +86 010-6273-7855 \\ 10 Received: date; Accepted: date; Published: date
}

11 Abstract:

Background: Monitoring armyworm (Mythimna separata Walker) damage in crops requires timely, rapid and accurate observations to avoid severe yield losses.

Results: The Random Forest (RF) classifier was more effective at automatically and accurately monitoring armyworm damage compared with Support Vector Machine (SVM), Multilayer Perceptron Classifier (MLPC) and Naive Bayes Classifier (NB) classifiers. Furthermore, the incorporation of an Unmanned Aerial Vehicle (UAV) image-generated digital surface model improved the performance of the RF classifier, increasing the F-score from 0.985 and 0.970 to 0.997 and 0.994, and increasing the Kappa coefficient from 0.955 to 0.990. In addition, we found that Band $3(735 \mathrm{~nm})$ of the UAV image and Band $6(740 \mathrm{~nm})$ of a coincident Sentinel-2 image were not sensitive to an armyworm infestation in this study.

Conclusions: We developed an accurate algorithm for the automated identification of armyworm-damaged corn plants using UAV images at the field scale. The study also indicated the feasibility of the developed method for monitoring corn armyworm damage at regional scale when combined with Sentinel-2 images.

Keywords: armyworm monitoring; summer corn; Unmanned Aerial Vehicle; Random Forest; Sentinel-2

\title{
Background
}

The incidence of insect pests in crops in China is increasing due to the frequent occurrence of extreme weather, simultaneous sowing over large areas and the increase of pests resistance to insecticides [1]. Curtis et al. [2] showed that crop pests increase with global temperatures and that an average global surface temperature increase of $2^{\circ} \mathrm{C}$ can lead to corn production declines of $23 \%$ in China and of $32 \%$ in the United States. Armyworm (Mythimna separata Walker) is one of the most serious insect pests for cereal crops and can result in great crop production losses every year [3, 4]. Summer corn is one of the favorite hosts of armyworm because high temperatures and rain during the growing season of summer corn make the crop grow rapidly and create a suitable environment for insect reproduction. Armyworm, with its high field density, long duration of the infestation and rapid migration [5], can result in devastating damages to corn. In 2012, one of the most serious armyworm infestations ever recorded broke out in most corn planted areas of China, covering about 7.4 million hectares [6]. Large losses of grain production lead to price increases in the agricultural product futures market when supply is low and demand is high, and vice versa. At present, 
application of chemical pesticides is the main method of armyworm control. However, the blind application of a large amount of pesticides damages the ecological environment and can leave pesticide residues harmful to human health. It is thus of great significance to rapidly and timely determine the occurrence area, severity and diffusion pattern of a pest infestation, so that precise spraying of pesticides in the field can be deployed with precision farming [7, 8]. Traditional methods of monitoring plant insect pests mainly depend on field inspection by plant protection personnel. This approach is time-consuming and laborious. Additionally, the field campaign can only be done in finite sampling areas and does not provide information about the degree of infestation over a region [9]. Armyworms mainly feed on corn leaves and ears, especially in the tasseling-filling stage, interfering with the normal physiological activities of corn and resulting in plant dwarfing and changed canopy spectra. In consideration of this fact, remote sensing can provide a promising approach for non-destructively identifying crop diseases and insect pests quickly and automatically on a regional scale.

Many studies have revealed the effectiveness of satellite images in monitoring crop diseases and insect pests. Yuan et al. [10] presented Fisher's linear discriminant analysis for monitoring crop diseases and pests based on the Worldview-2 and Landsat 8 satellite data. Chemura et al. [11] used Sentinel-2 images to discriminate coffee leaf rust infection levels and achieved high overall accuracy of $76.2 \%$. Meigs et al. [12] mapped tree mortality based on long time-series of Landsat images and forest inventory data and analyzed the spatiotemporal dynamics of insect pests. Unfortunately, the long revisit period, low spatial resolution and the requirements for clear weather of optical satellite images hampered the ability of monitoring armyworm infestations, which break out in short times $[13,14]$. Recently, unmanned aerial vehicles (UAV) with different sensors are increasingly being used in precision agriculture for monitoring crops growth condition [15-17]. With advances in the flexibility of operation and high spatial, spectral, and temporal resolution, UAV images can be used to accurately identify damaged plants and monitor their condition at the field scale $[18,19]$. Dobbels and Lorenz [20] used a UAV system to monitor soybean chlorosis caused by iron deficiency for developing tolerant soybean varieties and gained better results than those of traditional ground-based visual assessments. Yue et al. [21] extracted pest information from UAV images with an improved scale-invariant feature transform algorithm. Huang et al. [22] explored the potential of using the photochemical reflectance index for quantifying yellow rust in wheat from airborne hyperspectral images. Because UAVs can observe the land surface with high resolution images from different perspectives by flying on prescribed routes, UAV images can be used to generate digital surface models (DSM) through photogrammetry, such as with an image-based modeling (IBM) algorithm, offering a cost-effective way to collect crop canopy structure information [23, 24]. As a co-product of UAV optical imaging, the DSM can be used in crop land classification, crop growth monitoring, and yield estimation. Yang et al. [25] extracted the lodging area of rice successfully using UAV images and derived a DSM by developing a decision tree classification model with an accuracy of $96.17 \%$ and a Kappa coefficient of 0.941. Diaz-Varela et al. [26] automatically identified agricultural terraces by applying object-oriented classification to UAV multispectral images and high-resolution DSM, and their overall accuracy was $90 \%$. However, the joint use of UAV spectral images and DSM features for monitoring armyworm infestations is relatively less common in published studies.

Remote sensing data are massive and high-dimensional. Consequently, efficient and automated approaches are critical to their analysis and interpretation [27]. There are two groups of remote sensing image classification methods for pest identification: supervised classification methods, such as maximum likelihood method, machine learning method, and unsupervised classification methods, such as k-means and ISODATA. The Random Forest (RF) algorithm has been extensively used for monitoring the damage of pests on vegetation. RF is a machine learning method with ensemble learning, which uses multiple decision trees to predict samples [28, 29]. Because of ensemble learning, RF can avoid errors due to a single model or due to a single group of parameters; it has higher accuracy and better stability compared with using a single classifier. Moreover, it is not sensitive to abnormal values (noise) or overfitting [30] and is a nonparametric algorithm [31], which 


\section{Materials and Methods} Networks, etc.

\section{Study area}

means that it does not need to assume any parametric distribution of the data. Therefore, RF can be applied to various types of data [32]. In addition, RF can also output the importance of each feature to the classification and regression, helping feature selection to reduce data dimension and improve efficiency [33]. RF has been successfully applied to remote sensing images. Adelabu et al. [34] used RF and Support Vector Machine (SVM) classification algorithms to identify different levels of insect defoliation in an African savanna based on RapidEye imagery. Xu et al. [35] detected the damage of Dendrolimus punctatus Walker by Backpropagation neural networks and RF models. Aparecido et al. [36] developed a disease and pest warning system for coffee to predict the incidence of various diseases and insect pests by machine learning algorithm, such as the RF Regressor, Artificial Neural

In this study, we used the RF algorithm to identify the damage of armyworm in a summer corn field by extracting the pest damage from UAV images of the study area. The spectral characteristics of different incidences of the pest in Sentinel-2 images were also analyzed. The contributions of this paper were: i) to evaluate the performance of RF for monitoring the damage of armyworm as a pest of summer corn and compare it with other machine learning classifiers including SVM, Multilayer Perceptron Classifier (MLPC) and Naive Bayes Classifier (NB); ii) to explore the potential of corn canopy DSM for identifying the damage of corn armyworm; and iii) to identify the importance of the UAV image features for the identification of armyworm infestation.

The study area was located in Beicuizhuang Village, Langfang City, Hebei Province, China $\left(39^{\circ} 21^{\prime} \mathrm{N} \sim 39^{\circ} 22^{\prime} \mathrm{N}, 116^{\circ} 44^{\prime} \mathrm{E} \sim 116^{\circ} 46^{\prime} \mathrm{E}\right)$, in the central-eastern part of the North China Plain, covering an area of about 70 ha (Figure 1). There were various crops planted, including summer corn (mainly Zhengdan 958), soybean, peanut, fruit trees, and others. This is a typical small-holding farming area with flood irrigation by pumping water, so the crop management (e.g., sowing, irrigation, fertilization and weeding) is varied. Conventionally, in the study area, summer corn is seeded at the end of June and harvested in the beginning of October. Through on-site investigations and inquiries to local farmers, it was determined that the summer corn in this area was seriously attacked by armyworm in the middle of August 2019. 


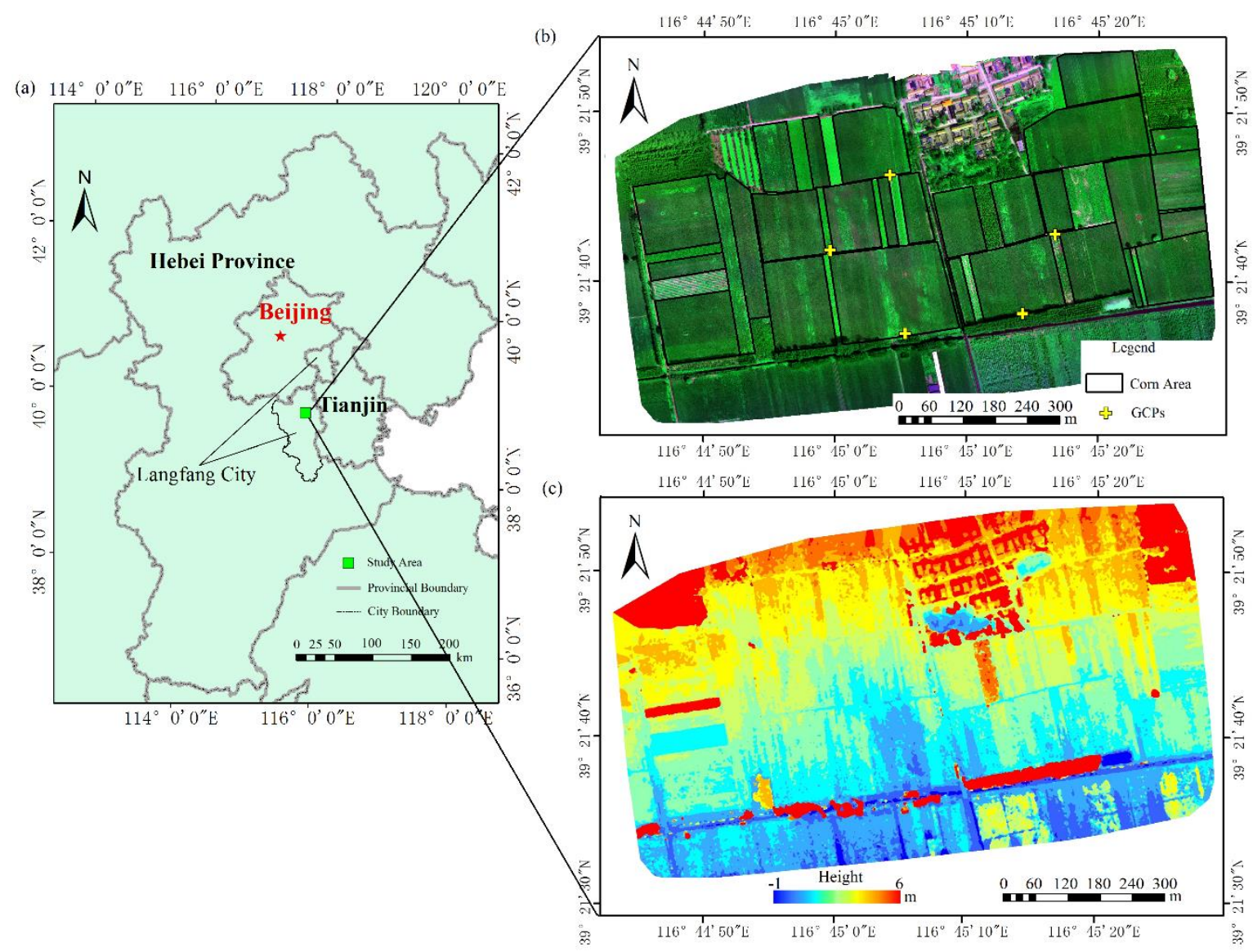

Figure 1. Study area: (a) location on the map; (b) UAV multispectral image, R/G/B=Band 2/ Band 3/ Band 1 of the experiment field; (c) UAV image-generated digital surface model (DSM).

\section{UAV image collection}

The UAV images were collected on 18 August 2019 between 10:50 and 11:25 local time, almost simultaneously with the acquisition time of a Sentinel-2 image. The meteorological conditions were sunny and windless. The Parrot Disco-Pro AG fixed-wing UAV system was used to collect the UAV images. The system, developed for agricultural applications, carried an automated multispectral sensor - the Parrot Sequoia camera (Table 1). The camera was connected to an irradiance sensor which had the same spectral bands as the multispectral sensor and recorded the light conditions [37].

Table 1. The band information of the Parrot Sequoia Multispectral sensor.

\begin{tabular}{ccc}
\hline Band & Central wavelength (nm) & Bandwidth \\
\hline Band 1- Green & 550 & 40 \\
Band 2- Red & 660 & 40 \\
Band 3- Red-edge & 735 & 10 \\
Band 4- NIR & 790 & 40 \\
\hline
\end{tabular}

Before the flight, the Parrot Sequoia camera took photos of the calibration board for radiation correction after photo splicing (Figure 2). The operator kept the calibration board facing the sun in order to guarantee there the absence of shadows on the board. Figure 2 (a)-(d) were the captured green, red, red-edge, and NIR band images for radiometric calibration in the study area. The aboveground height of the flight lines was 120 meters, the longitudinal overlap and lateral overlap were all $80 \%$, yielding a ground sample distance (GSD) of $0.135 \mathrm{~m} / \mathrm{pixel}$; the flight duration was 20 minutes. The georeferencing was achieved by Global Positioning System (GPS) built into the Parrot 
140

141

142

143

144

145

146

147

Sequoia camera and five ground control points (GCPs) were provided by using a Huace i80 real-time kinematic (RTK) GPS receiver (Huace Ltd., Shanghai, China) with $2.0 \mathrm{~cm}$ of positioning accuracy. In addition, the UAV photos, the calibration photos and GCPs were input into the Pix4Dmapper Pro 4.1 software following the "Ag Multispectral" template for automatic splicing and point cloud modeling [38]; finally, the spliced multispectral image (Figure 1b) and the UAV image-generated DSM (Figure 1c) were generated [23, 24], with spatial resolution of $0.135 \mathrm{~m} /$ pixel and accuracy of $0.131 \mathrm{~m}$. Therefore, the Parrot Disco-Pro AG fixed-wing UAV system was suitable for plot scale precision agricultural research.

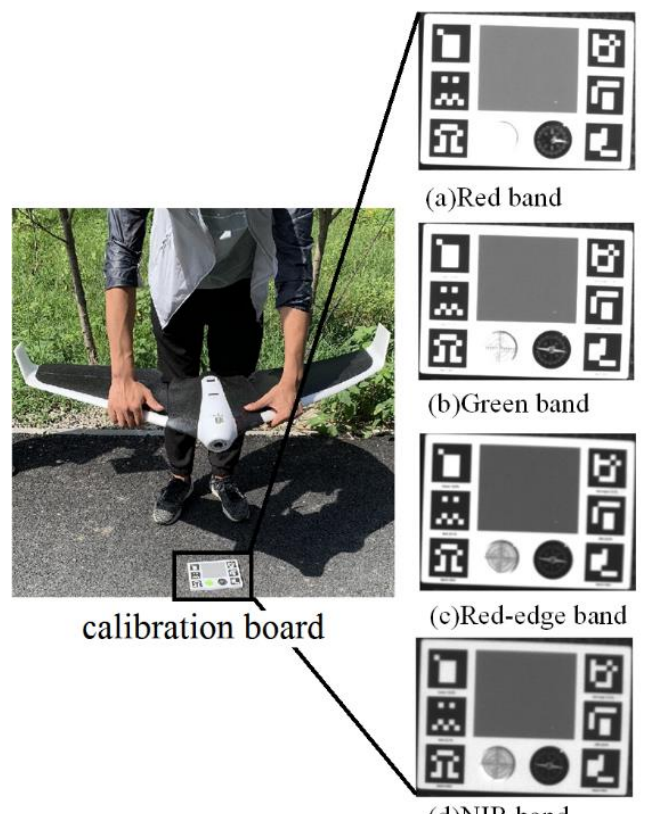

(d)NIR band

Figure 2. Shooting the calibration board on different bands.

\section{Sentinel-2 image acquisition and pre-processing}

Sentinel-2 images are one of the most widely used satellite multispectral images in view of their advantages in temporal, spatial and spectral resolution, and a free data policy. The cloudless Sentinel-2B Level-1C products used for this study were acquired on 18 August 2019 at 10:55 UTC with the UTM/WGS84 projection. The atmospheric correction of images was done by Sen2cor (version 2.8.0). The Sentinel-2 images adopted different spatial resolutions in different spectral bands (as shown in Table 2). Therefore, the SupReME algorithm [39] was used to generate a unified $10-\mathrm{m}$ resolution image set. The algorithm depended on the observation model of the imaging (blurring and down-sampling), and fully exploited the textural information from the high resolution bands and the correlation of spectral bands, to transfer all lower resolution bands to the maximum resolution quickly in one step. Existing studies have shown that such super-resolved images can improve the classification accuracy of images [40] and thus the ability of quantitative remote sensing [41]. Then, the spectral profiles of five different pest infection levels were extracted and analyzed based on the super-resolution images of Sentinel-2.

Table 2. List of Sentinel-2A image band parameters

\begin{tabular}{cccc}
\hline Band & Spatial resolution $(\mathbf{m})$ & Central wavelength $(\mathbf{n m})$ & Band width (nm) \\
\hline Band 1- Coastal aerosol & 60 & 443 & 20 \\
Band 2 - Blue & 10 & 490 & 65 \\
Band 3 - Green & 10 & 560 & 35 \\
Band 4 - Red & 10 & 665 & 30 \\
Band 5 - Red edge & 20 & 705 & 15 \\
Band 6 - Red edge & 20 & 740 & 15 \\
Band 7 - Edge of the NIR plateau & 20 & 783 & 20 \\
Band 8 - NIR & 10 & 842 & 115
\end{tabular}




\begin{tabular}{cccc} 
Band 8a - Narrow NIR & 20 & 865 & 20 \\
Band 9 - Water vapor & 60 & 945 & 20 \\
Band 11 - SWIR & 20 & 1610 & 90 \\
Band 12 - SWIR & 20 & 2190 & 180 \\
\hline
\end{tabular}

\section{4}

165

166

167

168

169

170

171

172

173

174

175

176

177

178

179

180

181

182

183

184

185

186

187

188

189

190

191

192

193

194

195

196

197

198

199

200

\section{Classification by machine learning algorithms}

The Scikit-learn open-source Python package [42] was used in this study to perform data classification and prediction by machine learning algorithms, including RF [28, 29], SVM [43], MLPC [44] and NB [45].

The damage of corn plants infected by armyworm shows with a decrease in leaves, which leads to changes in physiological activities, morphological characteristics and canopy spectrum of corn. The classifiers used image features to classify individual corn pixels into different categories. According to the ground survey and visual interpretation methods, there were 193,369 pixels of healthy corn plants; 96,825 pixels of corn damaged by armyworm were selected from UAV images with spatial resolution of $0.135 \mathrm{~m} /$ pixel. Furthermore, the datasets were used to create a dataset consisting of only UAV multispectral images and a dataset consisting of both UAV multispectral images and DSM information. A 10-fold cross-validation [46] was adopted to evaluate the accuracy of the classification. Through this approach, the dataset was divided randomly into ten groups, of which nine acted as training data and one group acted as the test data for training. The correct rate (or error rate) was obtained for each test. Finally, the average of the correct rate (or error rate) of ten iterations was used as the estimation of the accuracy of the algorithm. For the other three classifiers (SVM, MLPC and NB), the cross-validation method and the evaluation measures were the same as that for RF. Note that all test and validation datasets of the RF experiments were saved and used in the SVM, MLPC and NB classification experiments to ensure a fair comparison of these classifiers with RF.

Three measurements were used to assess the performance of the classifiers, including overall accuracy (OA), F score (F-health \& F-pest) and Kappa coefficient (Kappa) [47]. These measurements were calculated from a confusion matrix [48] of classification results (Figure 3). In Figure 3, TP (true positive) and FN (false negative) were the numbers of correct and wrong classifications of samples in the healthy corn category; FP (false positive) and TN (true negative) were the number of wrong and correct classifications of samples in the insect pest category.

The OA (Eq. 1) indicates the proportion of correctly predicted pixels including both healthy and attacked by insect pests. The F-score (Eq. 2) is an index that combines precision (p, Eq. 4) and recall (r, Eq. 5), and it is calculated for either healthy or infested corn. In Eq. 2, $\beta$ is to control the weights of $\mathrm{p}$ and $\mathrm{r}$ : when $\beta=1$, the two weights are the same; when $\beta>1$, the weight of $\mathrm{p}$ is significant; and when $\beta<1$, the weight of $r$ is significant. In this study, $\beta=1$. The Kappa coefficient (Eq.3) is a statistical indicator of interrater reliability [49], which is calculated by the OA and the probability of random agreement (Pe, Eq.6).

The RF classifier can perform an implicit feature selection to process the high-dimensional data efficiently. The outcome of this implicit feature selection of RF can be expressed with the Gini importance [32, 50] (Eq.7). In Eq. 7, $k$ is each of the classes analyzed and $P(k)$ is the proportion of observations in the $k_{-}$th class.

\begin{tabular}{c|c|c|}
\multicolumn{1}{c}{} & \multicolumn{2}{c}{ assignment } \\
Healthy & Insect attack \\
\cline { 2 - 3 } \multicolumn{1}{c}{ Healthy } & TP & FN \\
\cline { 2 - 3 } $\begin{array}{c}\text { Label } \\
\text { Insect attack }\end{array}$ & FP & TN \\
\cline { 2 - 3 } & &
\end{tabular}

Figure 3. Confusion matrix of separation results.

$$
\mathrm{OA}=\frac{\mathrm{TP}+\mathrm{TN}}{\mathrm{TP}+\mathrm{FN}+\mathrm{FP}+\mathrm{TN}}
$$




$$
\begin{aligned}
& \text { F score }=\left(1+\beta^{2}\right) \frac{r \times p}{r+\beta^{2} \times p} \\
& \text { Kappa }=\frac{\mathrm{OA}-\mathrm{Pe}}{1-\mathrm{Pe}} \\
& \mathrm{p}=\left\{\begin{array}{l}
\frac{\mathrm{TP}}{\mathrm{TP}+\mathrm{FP}} \text { Healthy } \\
\frac{\mathrm{TN}}{\mathrm{TN}+\mathrm{FN}} \text { Insect attack }
\end{array}\right. \\
& \mathrm{r}=\left\{\begin{array}{l}
\frac{\mathrm{TP}}{\mathrm{TP}+\mathrm{FN}} \text { Healthy } \\
\frac{\mathrm{TN}}{\mathrm{TN}+\mathrm{FP}} \text { Insect attack }
\end{array}\right. \\
& \mathrm{Pe}=\frac{(\mathrm{TP}+\mathrm{FN}) \times(\mathrm{TP}+\mathrm{FP})+(\mathrm{FP}+\mathrm{FN}) \times(\mathrm{FN}+\mathrm{TN})}{\mathrm{TP}+\mathrm{FN}+\mathrm{FP}+\mathrm{TN}} \\
& \text { Gini }=\sum k \times P(k) \times(1-P(k))
\end{aligned}
$$

\section{Results}

\section{Identification of armyworm damage with machine learning algorithms}

We evaluated the performance of the RF classifier using OA, F-health, F-pest, Kappa and running time. We compared the armyworm identification accuracy with UAV multispectral images alone with that obtained from combining the multispectral images with the DSM. The combination of DSM with the UAV multispectral images improved the performance of the RF classifier (Figure 4): the OA, F-health, F-pest, Kappa values improved while the running speed decreased, from 0.980 , $0.985,0.970,0.955$ and $69.6 \mathrm{~s}$ using multispectral UAV images alone to 0.996, 0.997, 0.994, 0.990 and $62.7 \mathrm{~s}$ by combining the multispectral UAV images and DSM, respectively. Particularly, the OA improved by 0.016 . The values of F-health, F-disease and Kappa were greater than 0.97 for both datasets, indicating that the RF classifier was highly accurate in distinguishing healthy corn from infested corn in this experiment.

Apart from RF, three classifiers were compared using these two types of datasets, including SVM, MLPC and NB classifiers (Figure 4). For these three classifiers, we observed the following three results. First, using the multispectral UAV images alone (Figure 4 (a)), the SVM had the best overall classification performance compared with MLPC and NB, with the OA, F-health, F-disease and Kappa values of $0.982,0.986,0.927$ and 0.959 respectively. The OA of SVM (0.982) was even higher than that of RF (0.980). Second, for the combined dataset of both multispectral UAV images and DSM (Figure 4 (b)), the NB had the highest classification accuracy, and the OA, F-health, F-disease and Kappa values were 0.988, 0.991, 0.982 and 0.972, respectively. The combination with the UAV image-generated DSM improved the performance of the NB classifier, in which the OA increased by 0.029 (from 0.959 for the multispectral images alone). Nonetheless, the OA of RF (0.996) was still higher than that of NB (0.988). Third, the running speed of the three classifiers was quite different. With our computing resources (Intel Core ${ }^{\mathrm{TM}} \mathrm{i7}-4790 \mathrm{CPU}$ and Win7 64-bit operating system), it took 3087.4s and 3176.2s for the MLPC method and 1488.1s and 1374.4s for the SVM method when using the multispectral UAV images and the combined multispectral images with DSM, respectively. This revealed that the addition of the UAV image-generated DSM could effectively speed up the running time of the machine learning classifiers (except for NB, but it was the fastest of the four classifiers). 

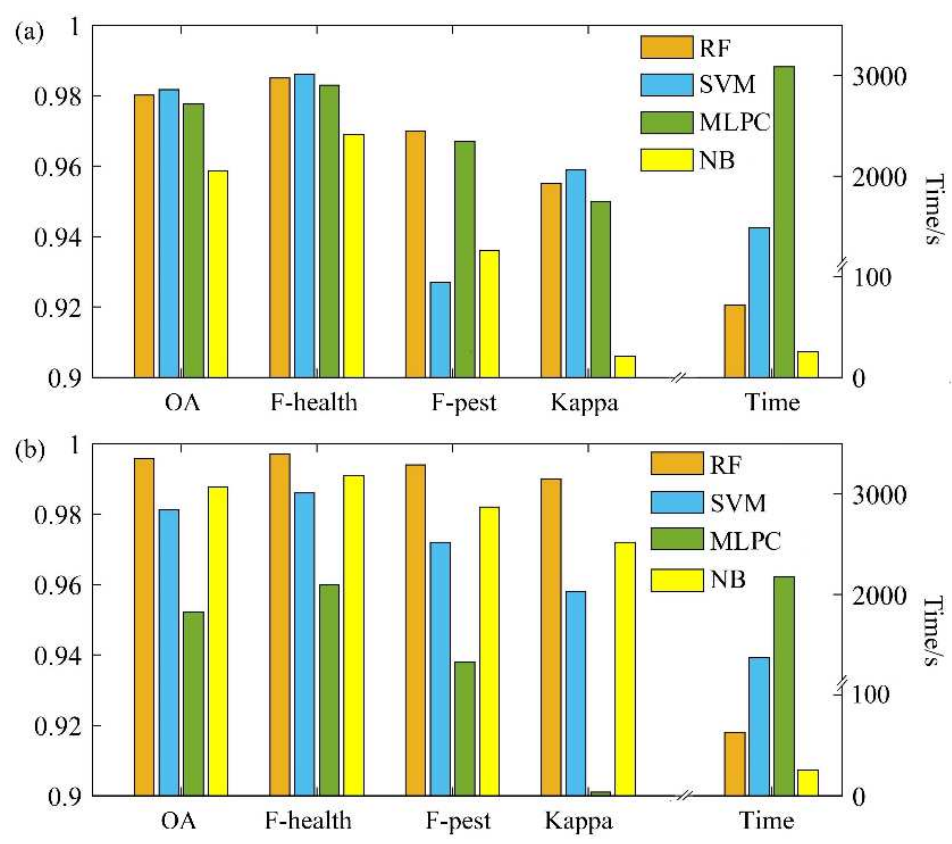

Figure 4. Results of the machine learning algorithms: (a) the multispectral images alone; (b) combined dataset (multispectral + DSM).

Figure 5 shows the distribution of the corn armyworm infestation obtained by applying the RF classifier to the UAV multispectral image and the DSM. The armyworm infestation mainly occurred in the southern portion of plot $A$, the top center of plot B and nearly the whole of plots $C$ and $D$. This is consistent with field observations. In the early stages of armyworm infestation, the farmers of plots $\mathrm{A}, \mathrm{B}, \mathrm{C}$ and $\mathrm{D}$ might have not found out in time or taken effective measures to prevent the spread of the pests; we also observed that in these plots the weeds, which were even higher than the corn plants, had not been removed in time, increasing humidity and limiting air circulation, which might have been one of the important reasons for the outbreak of armyworm [1, 6, 10]. Some field photos were taken at four points (p1)-(p4) in Figure 5. The photos in Figure 5 (b) and Figure $5(\mathrm{c})$ where from points attacked by armyworm in plots A and B, respectively. We can see that most of the corn leaves have been eaten by the armyworm, and only a small part of the stalk was left. For comparison, at points (p3) and (p4) there were no pests and the corn plants were healthy. 


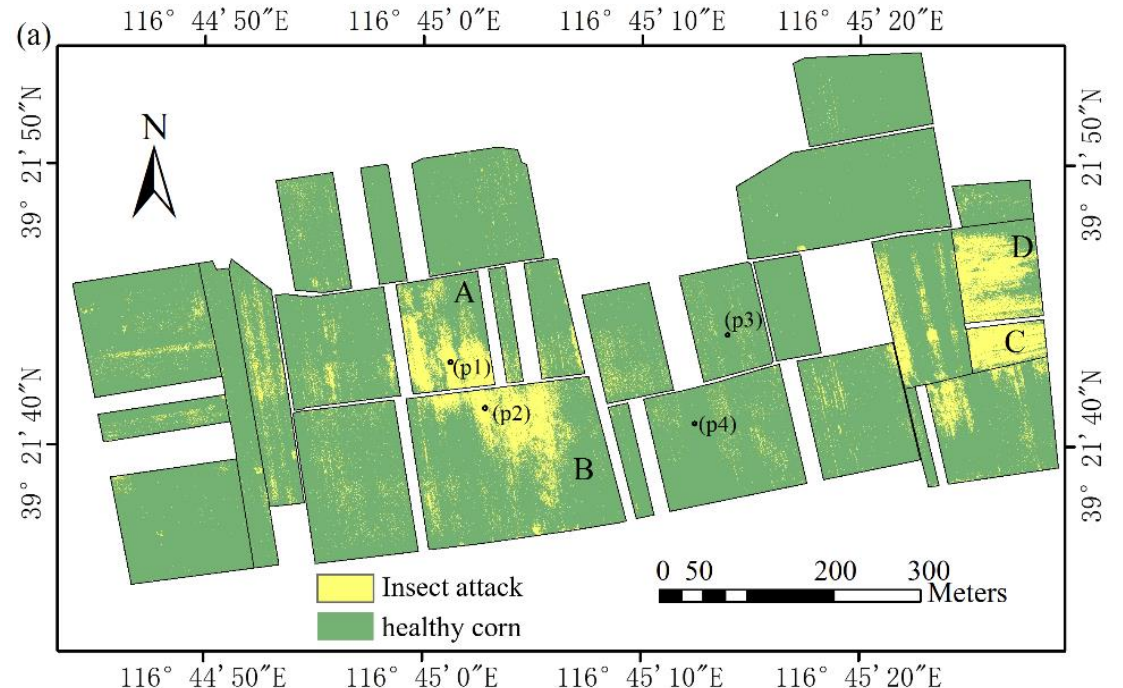

(b)

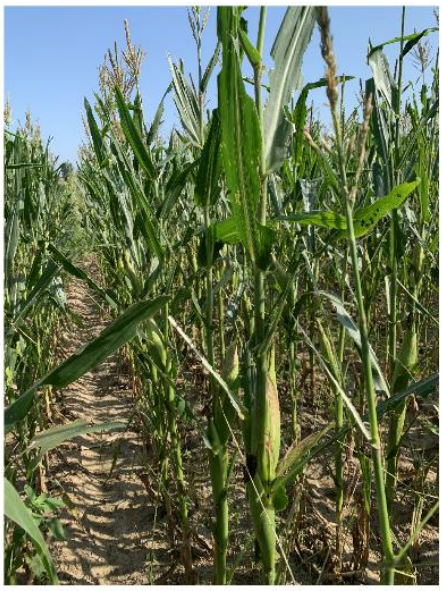

(d)

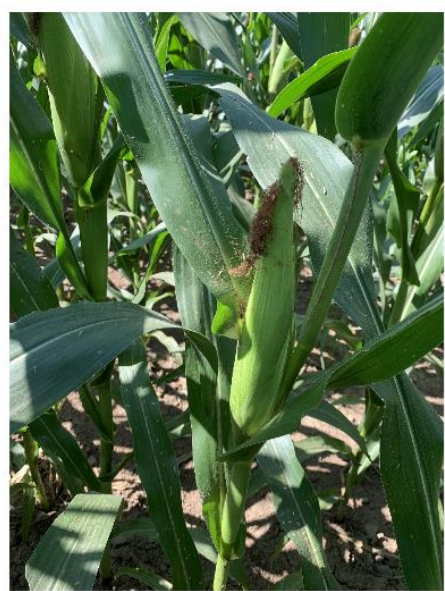

(c)

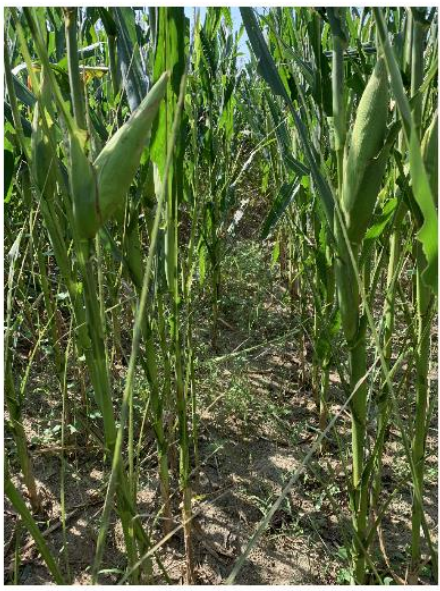

(e)

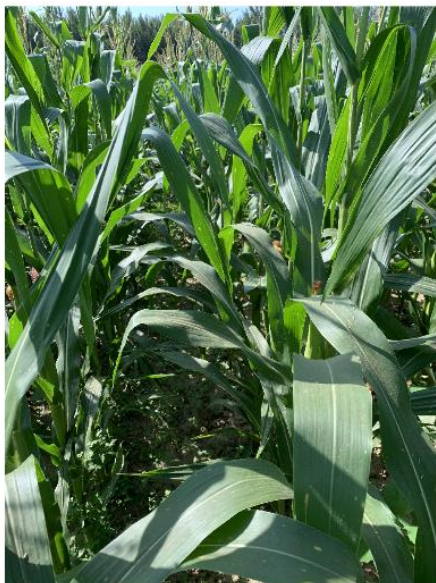

Figure 5. Monitoring of the armyworm attack on summer corn by RF: (a) map of corn damaged by armyworm; (b) and (c) are the photos of points (p1) and (p2) in the area damaged by armyworm, respectively; (d) and (e) are the photos of points (p3) and (p4) in the healthy area, respectively.

\section{Pest incidence levels classifying results}

The percentage of pest pixels in a $10 \mathrm{~m} \times 10 \mathrm{~m}$ grid (generated from the Sentinel-2 image) was calculated based on Figure 5 (a), and classified into five pest incidence levels of corn (Figure 6). The pest incidence is most serious in the southern portion of plot $A$, the top center of plot $B$ and whole of plots C and D, mostly $60 \%-100 \%$. This situation is consistent with field observations. In terms of 
incidence, plots $\mathrm{A}$ and $\mathrm{B}, \mathrm{C}$ and $\mathrm{D}$ are adjacent to each other, and the infested areas are connected. Therefore, that could be the cause of the local armyworm outbreak in the cornfield.

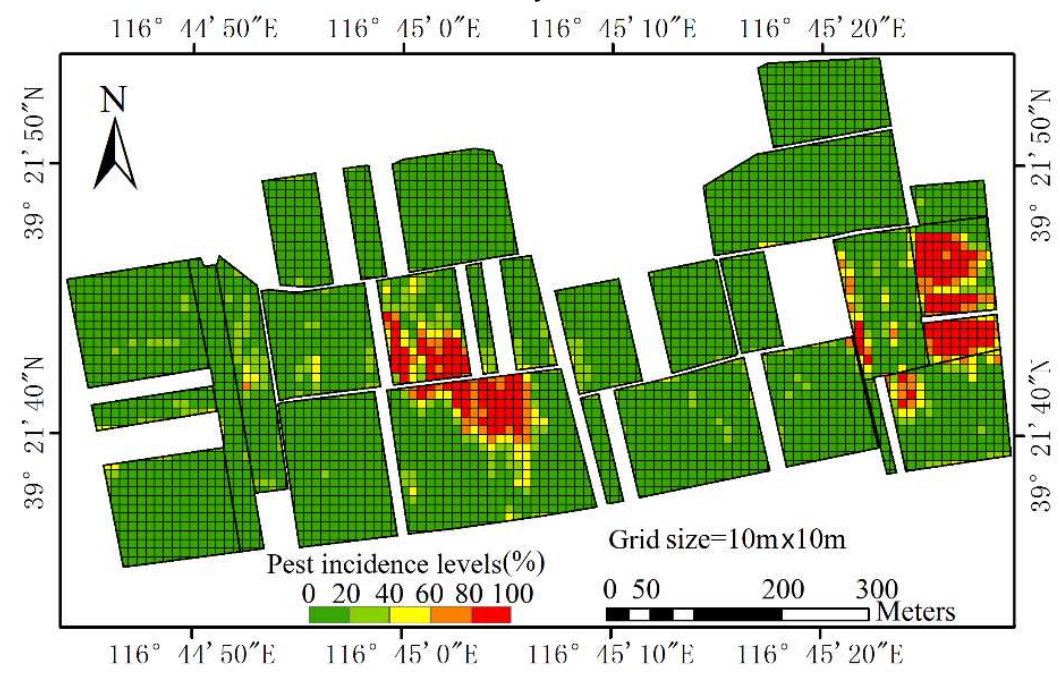

Figure 6. Pest incidence levels of corn in each $10 \times 10 \mathrm{~m}$ grid.

An infestation of armyworm in summer corn changes the canopy structure and affects the transmission path of light radiation, causing changes in canopy reflectance. The loss of leaves will also affect photosynthesis and transpiration of corn, and induce yellowing and withering of the plants because of inadequate nutrients and water, which further change the spectral characteristics of the corn canopy. The spectral characteristics of different levels of infestation of the Sentinel-2 image were analyzed (Figure 7). Figure 7 (a)-(e), (k) and (l) show that, as the infestation declines, the reflectivity of each band decreases, except at levels 4 to 5 . However, in Figure 7 (g)-(j), as the pest declines, the reflectivity of each band increases. In Figure 7 (f), the relationship between reflectivity and disease incidence is not very clear. 


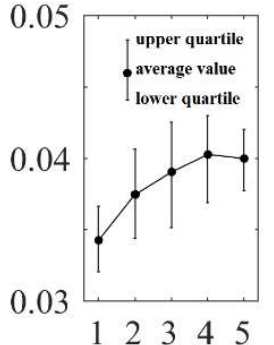

(a)

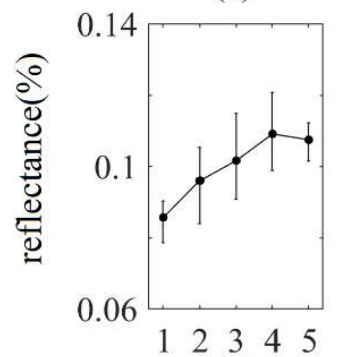

(e)

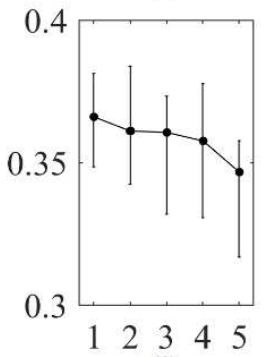

(i)

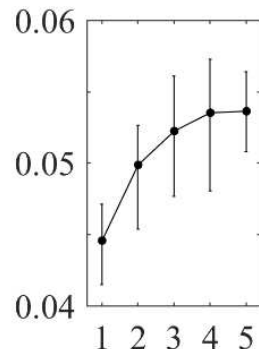

(b)

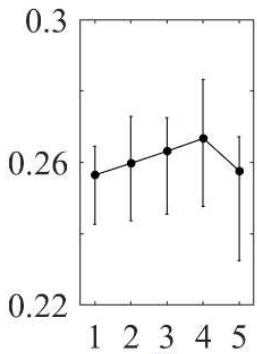

(f)

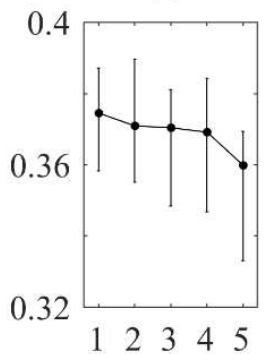

(j)

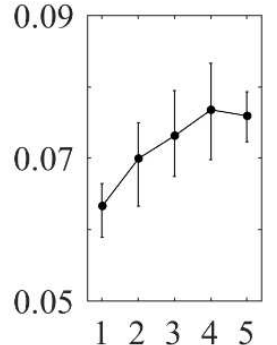

(c)

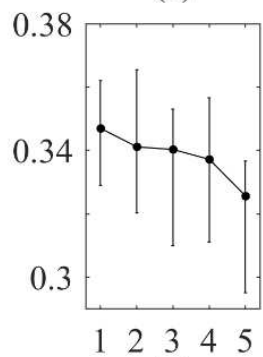

(g)

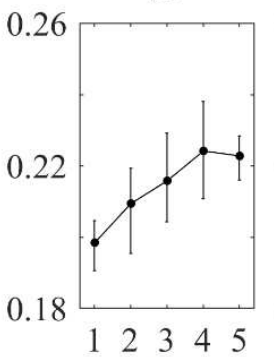

(k)

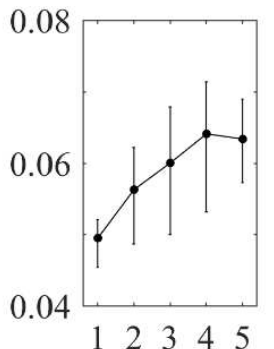

(d)

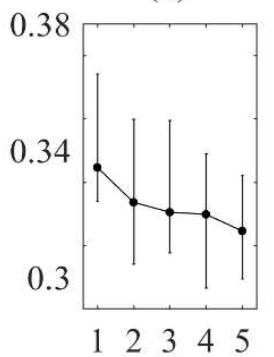

(h)

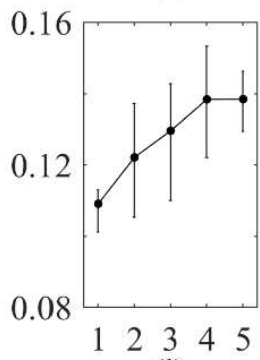

(1)

Figure 7. Spectral characteristics of different pest incidence levels in the Sentinel-2 image: the $\mathrm{x}$-axis represents levels of armyworm incidence (\%) in corn (0-20, 20-40, 40-60, 60-80, 80-100). Plots (a)-(1) correspond to Band 1-Band 8, Band 8a, Band 9, Band 11 and Band 12 of Sentinel-2.

\section{Discussion}

\section{Sensitivity to damage by armyworm}

To analyze the relationship between the five features of the UAV images (Band 1 - Green, Band 2 - Red, Band 3 - Red-edge, Band 4 - NIR and DSM) and classification accuracy, the Gini importance of each feature was calculated. In order of importance, the five features of the UAV images for the identification of armyworm diseases were Band 2 - Red (0.33) > Band 1 - Green (0.28) > DSM (0.21) > Band 4 - NIR (0.17) > Band 3 - Red-edge (0.01). It is clear that the three most important features for classification are the Red Band, the Green Band and the UAV image-generated DSM. The corn area damaged by armyworm (Figure 5 (a) and (b)) led to an abnormal canopy spectrum since the morphological and chemical characteristics of the leaves have an intense effect on the spectral characteristics of the canopy, which showed that the reflectivity of the red band and the green band increased and that of the NIR band decreased. Because the corn plants infested by armyworm are shorter than healthy ones, the DSM is also sensitive to the pests. The red-edge band is one of the most sensitive bands to vegetation diseases [51-53], and is located where the slope of the spectrum changes the most. However, contrary to our prior knowledge, the red-edge band $(735 \mathrm{~nm})$ has the lowest importance for classification in this case.

Figure 7 (e)-(g) were the spectral characteristics of Band 5, Band 6 and Band 7 with corn armyworm incidence (\%) at 0-20, 20-40, 40-60, 60-80, 80-100 intervals, respectively. These three narrow bands were red-edge bands which was very sensitive to vegetation changes, lying between 
the Red band and the NIR band. The central wavelengths of these three red-edge bands, which have the largest slope change in the whole spectrum, were $705 \mathrm{~nm}, 740 \mathrm{~nm}$ and $783 \mathrm{~nm}$, respectively. The spectral range of Band 6 of the Sentinel-2 image corresponds to Band 3 of the UAV image (Table 1). With the decrease of corn armyworm, the reflectance of Band 5 decreases and that of Band 7 increases. Band 6 of Sentinel-2 $(740 \mathrm{~nm})$ and Band 3 - Red-edge of UAV (735 nm) were between the changes of Band 5 and Band 7, and the spectral intervals for these three bands was only about $40 \mathrm{~nm}$, which makes the sensitivity of the two bands to the pest change lower than other bands [54,55]. This revealed that Band 6 was not sensitive to the damage of corn armyworm in this study. This result was consistent with the ranking of the feature importance in the RF output.

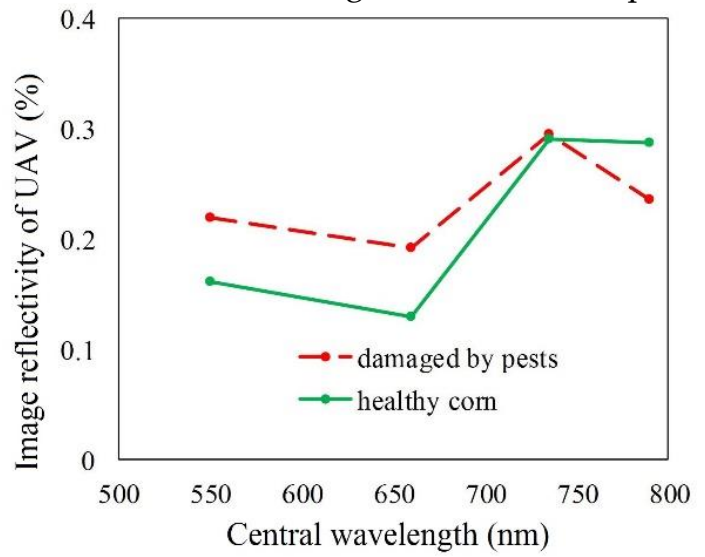

Figure 8. Canopy spectral response of UAV image in summer corn

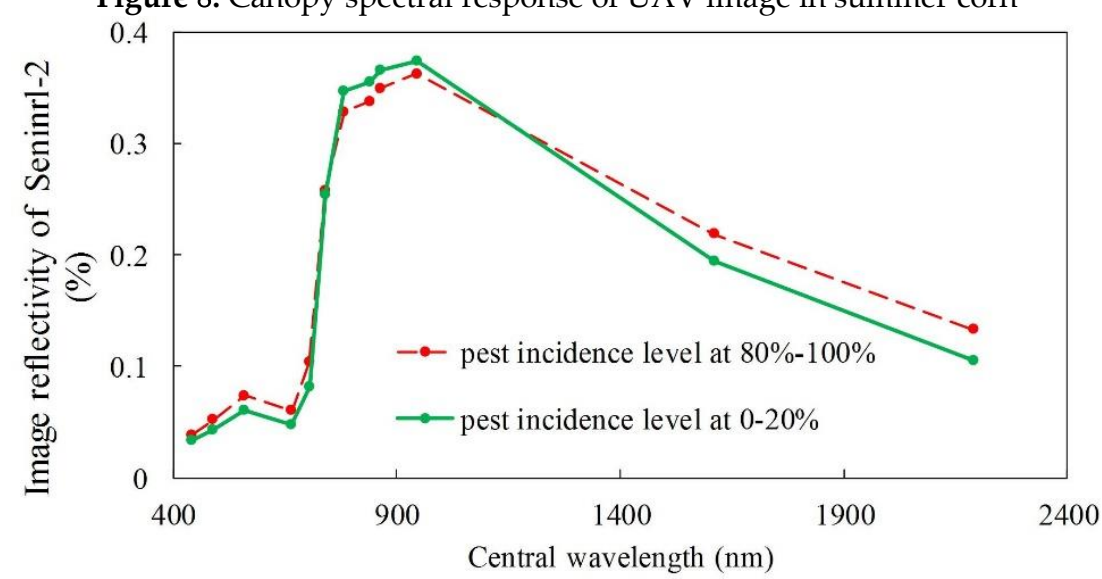

Figure 9. Canopy spectral response of Sentinel-2 image in summer corn

The infestation of armyworm in corn growth leads to changes in leaf area of the affected tissue or plant directly $[9,10]$. As the main organ of photosynthesis and other physiological activities, the loss of leaves causes a domino effect in the corn plants. As the plants lack sufficient nutrients and water to sustain the various physiological activities, the concentration of chemical pigments in tissues declines, and the cell and tissue structure is destroyed. Figure 8 shows the UAV image representative average reflectance from the corn area damaged by pests and healthy summer corn canopies. The reflectance of corn damaged by pests is higher than that of healthy corn in Band 1 Green and Band 2 - Red, and it is lower than that of healthy corn in Band 4 - NIR. However, in Band 3 -Red-edge, the reflectance is almost the same in both cases. Figure 9 shows the Sentinel-2 representative average reflectance from the armyworm infested (pest incidence level at $80 \%-100 \%$ ) and healthy (pest incidence level at $0 \%-20 \%$ ) summer corn canopies. The two curves intersect at two inflection points, located at about $740 \mathrm{~nm}$ and $1150 \mathrm{~nm}$, respectively. The armyworm damage area has higher canopy reflectance from $443 \mathrm{~nm}$ to $705 \mathrm{~nm}$ and from $1610 \mathrm{~nm}$ to $2190 \mathrm{~nm}$ than healthy summer corn. From 783-945 nm, the canopy reflectance from healthy summer corn is higher when than that of armyworm damage area. This indicates that a reduced amount of leaves in the corn canopy influences the light distribution. In Figure 7 and Figure 9, the section of 443-665 nm was located in the visible spectrum band where the leaves could rely on various pigments (i.e., chlorophyll, carotenoids) to absorb this energy. The decrease of corn canopy pigment led to the 
decrease of visible light absorption, which resulted in the increase of canopy reflectance of this part of the spectrum (Figure 7 (a)-(d)). The canopy spectrum of 783-945 nm in the near-infrared band tends to be highly reflective and is closely related to the cell structure. The canopy reflectance at 783-945 $\mathrm{nm}$ was lower than that of healthy corn, indicating that the armyworm had seriously damaged the cell structure of the plants (Figure 7 (g)-(j)). From 443-945 nm, the red edge position shifted to a shorter wavelength due to the infestation of armyworm, with a "Red Edge-Blue Shift" in the spectrum, which decreased the slope of the red edge. Moreover, from $1610 \mathrm{~nm}$ to $2190 \mathrm{~nm}$, the canopy reflectance is related to the water content of vegetation. In the area damaged by armyworm, the leaves of vegetation canopy decreased, the plants gradually withered, and the water content decreased, which led to the increase in spectral reflectance compared to that of normal vegetation (Figure 7 (k)-(l)).

\section{Broader implications for future agriculture applications}

First, our study shows the effectiveness of the RF classifier in mapping damages of armyworm infestation based on UAV images, especially when information about the canopy structure (i.e., the DSM) is added. Armyworm mainly eats the leaves and ears of corn, directly damaging the canopy structure, changing the physiological activities, morphological characteristics and canopy spectrum of corn $[8,56]$. In general, canopy structural features could supplement information on the health status of crops, and improve the accuracy of the identification of armyworm damage area [57, 58].

Second, in this study, four machine learning classifiers, RF, SVM, MLPC and NB, were used to extract the regions in which armyworm outbreaks occurred in the field, with OA of more than 95\%, with the OA of RF reaching 99.57\%, indicating the advantages of applying machine learning classifiers to agricultural applications. Agricultural remote sensing also includes many crop growth simulation models (e.g., WOFOST, DSSAT) and radiation transfer models (e.g., PROSAIL, DART), which can accurately describe material and energy exchanges between crops and the external environment [55, 59-61]. However, these models are often complex and cannot directly retrieve crop growth parameters. Combining these models with machine learning techniques can improve the retrieval of crop growth parameters [62-64].

Third, as a low-cost, flexible and easy to operate field monitoring method, UAV remote sensing is playing an increasingly important role in agricultural development. Using UAV images, we can quickly understand the growth of crops in the field, and quickly identify the region and level of infestation of armyworm [24]. As a large agricultural country, China represents a broad application prospect for agricultural insurance. However, rapid and accurate claim settlements have always been a problem hindering the development of the agricultural insurance industry. The application of UAV in insect pest identification, damage assessment and yield estimation can provide effective means for the rapid settlement of agricultural insurance claims. In addition, we can combine multi-temporal UAV images and satellite images to dynamically detect insect pests in the field, understand the source and diffusion patterns of pests, and manage the farmland more intelligently.

\section{Conclusions}

Armyworm is one of the most serious insect pests of corn. In this paper, we proposed a method to successfully monitor the damage of armyworm as a pest in summer corn in the study area based on UAV images and the RF algorithm.

The conclusions that can be drawn from this study are as follows: 1) RF could monitor the damage of armyworm (Mythimna separata Walker) infestation on summer corn by UAV images from the heading stage to the milk stage in the study area; 2) the addition of UAV image-generated DSM will not only improve the classification accuracy of RF, but also improve its operation efficiency; 3) the order of importance of five features of UAV for the identification of armyworm is Band $2>$ Band $1>$ DSM $>$ Band $4>$ Band 3, while Band $3(735 \mathrm{~nm})$ of UAV and Band 6 (740nm) of Sentinel-2 are not sensitive to pest information in this study. 
However, due to the small geographical coverage of UAVs, our experimental area is relatively small. In the future, we will expand our research to explore the armyworm infestation of other similar crops (wheat and rice) and monitor the damage of insect pest on a larger scale.

Author Contributions: This work was a cooperation of our research team, and the contributions were as follows: Conceptualization, Mingzheng Zhang, Jing-Hao Xue and Wei Su; Formal analysis and Writing review \& editing, Jing-Hao Xue; Investigation, Xinsheng Wang, Wei Su and Dehai Zhu; Methodology and Writing - original draft, Mingzheng Zhang; Software, Mingzheng Zhang and Wancheng Tao; Validation, Zixuan Xie, Tian Jin and Chan Yao.

Funding This study was funded by the National Natural Science Foundation of China under the projects (No. 41671433 and No. 41371327), the National Key Research and Development Program of China (No. 2017YFD0300903), the Chinese Universities Scientific Fund (No. 2019TC138 and No. 2019TC117), and the Science and Technology Facilities Council of the UK-Newton Agri-tech Programme (No. ST/N006798/1).

\section{Availability of data and materials}

The datasets used and/or analyzed during the current study available from the corresponding author on reasonable request.

Acknowledgments: We thank the farmers for allowing us to make use of their fields for measurements.

\section{Ethics approval and consent to participate}

Not applicable.

\section{Consent for publication}

Not applicable.

\section{Competing interests}

The authors declare that they have no competing interests.

\section{Author details}

\section{References}

1. Liu J, Zeng J, Jiang Y, Liu L, Zhu J, Bao S. Occurring characteristics and related factors of major corn diseases and insect pests in 2018 in China. China Plant Protection. 2019;2:43-49. (In Chinese with English abstract)

2. Curtis AD., Joshua JT., Michelle T., David SB., Scott CM., Raymond BH., Rosamond L., N. Increase in crop losses to insect pests in a warming climate. Science. 2018;361: 916-919.

3. Hassan Y., Naeem A., Li Y., Zhang Y. Selection for resistance, life history traits and the biochemical mechanism of resistance to thiamethoxam in the maize armyworm, mythimna separata (lepidoptera: noctuidae). Phytoparasitica. 2018:4.

4. Strange RN., Scott PR. Plant Disease: A Threat to Global Food Security. Annual Review of Phytopathology. 2015;43:83-116.

5. Sharma HC, Davies JC. The Oriental Armyworm, Mythimna separata (Walk.) Distribution, biology and control: a literature review. Miscellaneous Report No 59. Miscellaneous Reports - Centre for Overseas Pest Research (UK), 1983.

6. Liu J., Jiang Y. Characteristic of Corn Diseases and Pest in 2012 and Cause Analysis. Chinese Agricultural Science Bulletin. 2014;30:270-279. (In Chinese with English abstract)

7. Godfray HCJ., Beddington JR., Crute I R., Haddad, L., Lawrence, D., Muir, J., F., Jules, P., Sherman, R., Sandy, M., T., Camilla, T. Food security: the challenge of feeding 9 billion people. Science. 2010;327:812-818.

8. Piao S., Ciais P., Huang Y., Shen Z., Peng S., Li J., Zhou L., Liu H., Ma Y., Ding Y., Pierre F., Liu C., Tan K., Yu Y., Zhang T., Fang J. The impacts of climate change on water resources and agriculture in china. Nature. 2010;467:43-51.

9. Klauser D. Challenges in monitoring and managing plant diseases in developing countries. Journal of Plant Diseases \& Protection. 2018;125:235-237. 
10. Yuan L, Bao Z, Zhang H, Zhang Y, Liang X. Habitat monitoring to evaluate crop disease and pest distributions based on multi-source satellite remote sensing imagery. Optik - International Journal for Light and Electron Optics. 2017;145.

11. Chemura A, Mutanga O, Dube T. Separability of coffee leaf rust infection levels with machine learning methods at sentinel-2 msi spectral resolutions. Precision Agriculture. 2016;1-23.

12. Meigs GW, Kennedy RE, Gray AN, Gregory MJ. Spatiotemporal dynamics of recent mountain pine beetle and western spruce budworm outbreaks across the Pacific Northwest Region, USA. Forest Ecology and Management. 2015;339:71-86.

13. Eklundh L, Johansson T, Solberg S. Mapping insect defoliation in Scots pine with MODIS time-series data. Remote Sens. Environ. 2009;113:1566-1573.

14. Zhang M, Zhu D, Su W, Huang J, Zhang X, Liu Z. Harmonizing Multi-Source Remote Sensing Images for Summer Corn Growth Monitoring. Remote Sens. 2019;11:1266.

15. Su W, Zhang MZ, Bian DH, Liu Z, Huang JX, Wang W, Wu JY, Guo H. Phenotyping of Corn Plants Using Unmanned Aerial Vehicle (UAV) Images. Remote Sens. 2019;11:2021.

16. Ludeno G, Catapano I, Renga A, Vetrella AR, Fasano G, Soldovieri F. Assessment of a micro-UAV system for microwave tomography radar imaging. Remote Sens. Environ. 2018;212:90-102.

17. Colomina I, Molina P. Unmanned aerial systems for photogrammetry and remote sensing: A review. ISPRS Journal of Photogrammetry and Remote Sensing. 2014;92: 79-97.

18. Zarco-Tejada PJ, V González-Dugo, Berni JAJ. Fluorescence, temperature and narrow-band indices acquired from a UAV platform for water stress detection using a micro-hyperspectral imager and a thermal camera. Remote Sens. Environ. 2012;117:0-337.

19. Vanegas AF, Bratanov D, Powell K, Weiss J, Gonzalez L. A Novel Methodology for Improving Plant Pest Surveillance in Vineyards and Crops Using UAV-Based Hyperspectral and Spatial Data. Sensors. 2018;18:260.

20. Dobbels AA, Lorenz AJ. Soybean iron deficiency chlorosis high-throughput phenotyping using an unmanned aircraft system. Plant Methods. 2019;15(1):97.

21. Yue J, Lei T, Li C, Zhu J. The application of unmanned aerial vehicle remote sensing in quickly monitoring crop pests. Intelligent Automation \& Soft Computing. 2012:18:1043-1052.

22. Huang W, Lamb DW, Niu Z, Zhang Y, Liu L, Wang J. Identification of yellow rust in wheat using in-situ spectral reflectance measurements and airborne hyperspectral imaging. Precision Agriculture. 2007;8:187-197.

23. Zarco-Tejada PJ, Diaz-Varela R, Angileri V, Loudjani P. Tree height quantification using very high resolution imagery acquired from an unmanned aerial vehicle (UAV) and automatic $3 \mathrm{~d}$ photo-reconstruction methods. European Journal of Agronomy. 2014;55:89-99.

24. Dash JP, Watt MS, Pearse GD, Heaphy M, Dungey HS. Assessing very high resolution uav imagery for monitoring forest health during a simulated disease outbreak. ISPRS Journal of Photogrammetry and Remote Sensing, 2017;131:1-14.

25. Yang M, Huang K, Kuo Y, Hui T, Lin L. Spatial and spectral hybrid image classification for rice lodging assessment through UAV imagery. Remote Sensing. 2017;9:583.

26. Diaz-Varela RA, Zarco-Tejada PJ, Angileri V, Loudjani P. Automatic identification of agricultural terraces through object-oriented analysis of very high resolution dsms and multispectral imagery obtained from an unmanned aerial vehicle. Journal of Environmental Management. 2014;134:117-126.

27. Andrés T, Gancarski P, Berti-Equille L. Remote sensing image analysis by aggregation of segmentation-classification collaborative agents. Pattern Recognition. 2018;73:259-274.

28. Breiman L. RFs. Machine Learning. 2011;45:5-32.

29. Svetnik V. RF: A Classification and Regression Tool for Compound Classification and QSAR Modeling. J. Chem. Inf. Comput. Sci. 2003;43.

30. Clark ML, Roberts DA. Species-Level Differences in Hyperspectral Metrics among Tropical Rainforest Trees as Determined by a Tree-Based Classifier. Remote Sensing. 2012;4:1820-1855.

31. Oliveira S, Oehler F, San-Miguel-Ayanz J, Camia A, Pereira JMC. Modeling spatial patterns of fire occurrence in Mediterranean Europe using Multi Regression and RF. For. Ecol. Manage. 2012;275: 117-129.

32. Cutler A, Cutler DR, Stevens JR. RFs. Machine Learning. 2011;45:157-176.

33. Belgiu M, Lucian D. RF in remote sensing: a review of applications and future directions. ISPRS Journal of Photogrammetry and Remote Sensing. 2016;114:24-31. 
34. Adelabu S, Mutanga O, Adam E. Evaluating the impact of red-edge band from Rapideye image for classifying insect defoliation levels. ISPRS Journal of Photogrammetry and Remote Sensing. 2014;95(sep.):34-41.

35. Xu Z, Huang X, Lin L, Liu J, Yu K, Chen C. BP neural networks and random forest models to detect damage by Dendrolimus punctatus Walker. J. For. Res. 2020;31:107-121.

36. Aparecido LEDO, Rolim GDS, José R, Costa, CTS, Paulo S. Machine learning algorithms for forecasting the incidence of coffea arabica pests and diseases. International Journal of Biometeorology. 2019;64(3).

37. Ahmed OS, Shemrock A, Chabot D, Dillon C, Franklin SE. Hierarchical land cover and vegetation classification using multispectral data acquired from an unmanned aerial vehicle. International Journal of Remote Sensing. 2017;38:2037-2052.

38. Fernández-Guisuraga J, Enoc SA, Suárez-Seoane S, Leonor C. Using unmanned aerial vehicles in postfire vegetation survey campaigns through large and heterogeneous areas: opportunities and challenges. Sensors. 2018;18:586.

39. Lanaras C, Bioucas-Dias J, Baltsavias E, Schindler K. Super-Resolution of multispectral multiresolution images from a single sensor. IEEE Computer Society Conference on Computer Vision and Pattern Recognition Workshops. 2017;1505-1513.

40. Zheng H, Du P, Chen J, Xia J, Li E, Xu Z, Li X, Yokoya N. Performance evaluation of downscaling sentinel-2 imagery for land use and land cover classification by spectral-spatial features. Remote Sensing. 2017;9:1274.

41. Zhang M, Su W, Fu Y, Zhu D, Xue J, Huang J, Wang W, Wu J, Yao C. Super-resolution enhancement of Sentinel-2 image for retrieving LAI and chlorophyll content of summer corn. Eur. J. Agron. 2019; 111:125938.

42. Ashish S, Ritesh J. Scikit-learn: Machine Learning in Python. Journal of Machine Learning Research. 2012;12:2825-2830.

43. Satoru K, Abdallah Z, Farid M, Ryuei N. Spatial and structured svm for multilabel image classification. IEEE Transactions on Geoscience and Remote Sensing. 2008;1-13.

44. Zhao C, Gao Y, He J, Lian J. Recognition of driving postures by multiwavelet transform and multilayer perceptron classifier. Engineering Applications of Artificial Intelligence. 2012;25:1677-1686.

45. Wang Q, Garrity GM, Tiedje JM, Cole JR. Naive bayesian classifier for rapid assignment of rRNA sequences into the new bacterial taxonomy. Applied and Environmental Microbiology. 2007;73: 5261-5267.

46. Rodriguez JD, Perez A, Lozano JA. Sensitivity analysis of k-fold cross validation in prediction error estimation. IEEE Transactions on Pattern Analysis and Machine Intelligence. 2010;32:569-575.

47. Vicari MB, Disney M, Wilkes P, Burt A, Calders K, Woodgate W. Leaf and wood classification framework for terrestrial lidar point clouds. Methods in Ecology and Evolution. 2019;10:680-694.

48. Goutte C, Gaussier E. A Probabilistic Interpretation of Precision, Recall and F score, with Implication for Evaluation. Advances in Information Retrieval. 2005;3408:345-359.

49. Cohen J. A coefficient of agreement for nominal scales. Educ. Psychol. Measur. 1960;20:37-46.

50. Menze B, Kelm B, Masuch R, Himmelreich U, Bachert P, Petrich W, Hamprecht F. A comparison of random forest and its gini importance with standard chemometric methods for the feature selection and classification of spectral data. BMC Bioinformatics. 2009;10:213-0.

51. Ramoelo A, Skidmore A, Cho M, Schlerf M, Mathieu R, Heitkonig I. Regional estimation of savanna grass nitrogen using the red-edge band of the spaceborne rapideye sensor. International Journal of Applied Earth Observation and Geoinformation. 2012;19:151-162.

52. Adelabu S, Mutanga O, Adam E. Evaluating the impact of red-edge band from rapideye image for classifying insect defoliation levels. ISPRS Journal of Photogrammetry and Remote Sensing. 2014;95:34-41.

53. Shafri HZM, Nasrulhapiza H. Hyperspectral imagery for mapping disease infection in oil palm plantationusing vegetation indices and red edge techniques. American Journal of Applied Sciences. 2009;6(6).

54. Qiong Z, Wenjiang H, Ximin C, Yue S, Linyi L. New spectral index for detecting wheat yellow rust using sentinel-2 multispectral imagery. Sensors. 2018;18(3):868.

55. Zhang J, Pu R, González-Moreno P, Yuan L, Wu K, Huang W. Monitoring plant diseases and pests through remote sensing technology: A review. Computers and Electronics in Agriculture. 2019:165;104943.

56. Mahlein AK, Oerke EC, Steiner U, Dehne HW. Recent advances in sensing plant diseases for precision crop protection. European Journal of Plant Pathology. 2012;133:197-209. 
57. Wang L, Zheng N, Hanyue C, Dong L. Characterizing canopy structural complexity for the estimation of maize LAI based on ALS data and UAV stereo images. International Journal of Remote Sensing. 2016;38(8):1-11.

58. Cecchi G, Magli R, Mazzinghi P, Pantani L, Pippi I. Vegetation Remote-Sensing: A New Field for Lidar Applications. European Conference on Optics.1985.

59. Maruyama A, Kuwagata T. Coupling land surface and crop growth models to estimate the effects of changes in the growing season on energy balance and water use of rice paddies. Agric. For. Meteorol. 2010;150:0-930.

60. Huang J, Gómez-Dans J, Huang H, Ma H, Wu Q, Lewis P, Liang S, Chen Z, Xue J, Wu Y, Zhao F, Wang J, Xie X. Assimilation of remote sensing into crop growth models: current status and perspectives. Agric. For. Meteorol. 2019;276-277.

61. Su W, Huang JX, Liu DS, Zhang MZ. Retrieving Corn Canopy Leaf Area Index from Multitemporal Landsat Imagery and Terrestrial LiDAR Data. Remote Sensing. 2019;11:572.

62. Doktor D, Lausch A, Spengler D, Thurner M. Extraction of plant physiological status from hyperspectral signatures using machine learning methods. Remote Sensing. 2014;6:12247-12274.

63. Verrelst J, Rivera JP, Gitelson A, Delegido J, Moreno J, Camps-Valls G. Spectral band selection for vegetation properties retrieval using gaussian processes regression. International Journal of Applied Earth Observation and Geoinformation. 2016;52:554-567.

64. Zhuo W, Huang J, Li L, Zhang X, Ma H, Gao X, Huang H, Xu B, Xiao X. Assimilating Soil Moisture Retrieved from Sentinel-1 and Sentinel-2 Data into WOFOST Model to Improve Winter Wheat Yield Estimation. Remote Sens. 2019;11:1618. 


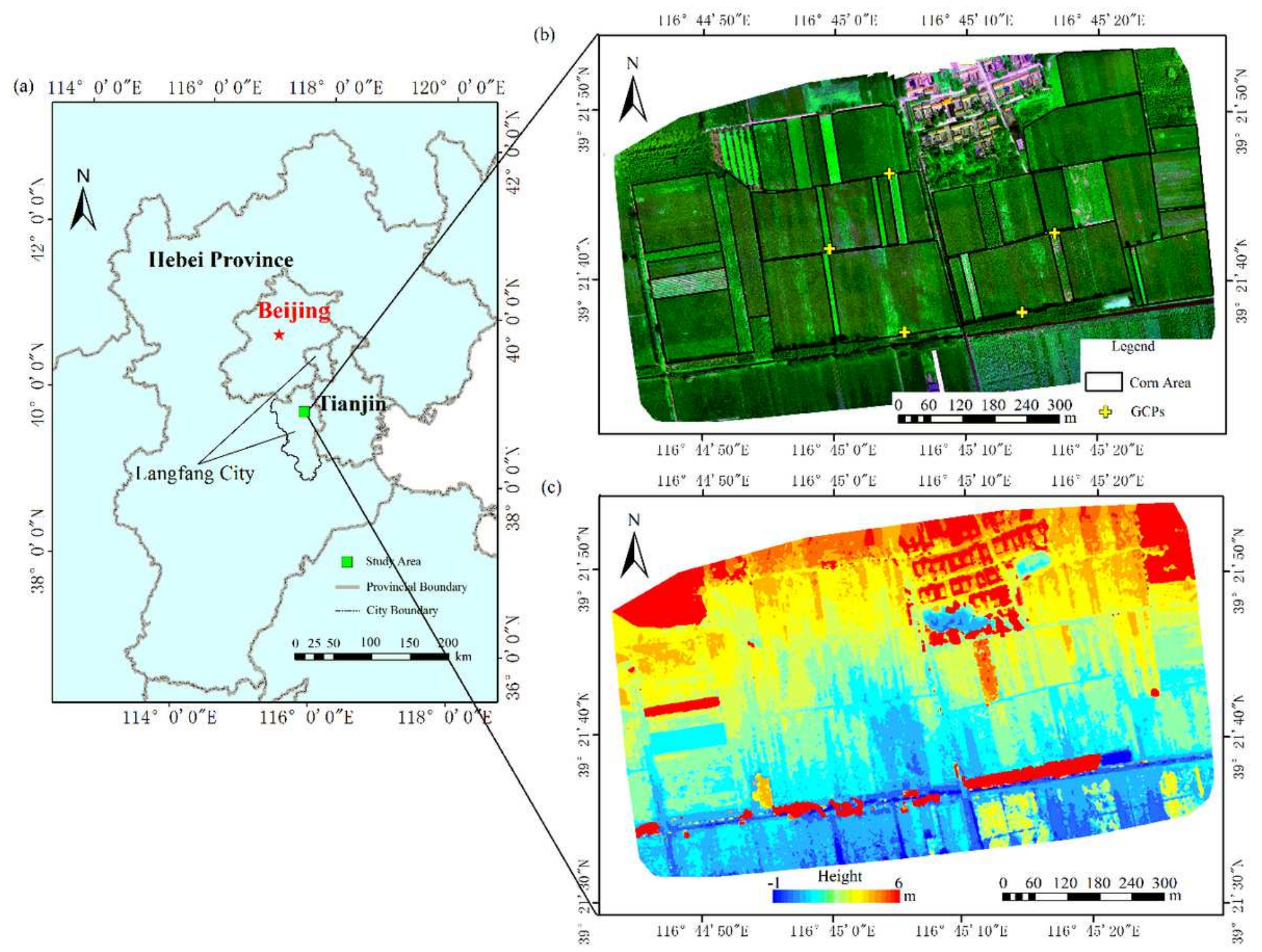

\section{Figure 1}

Study area: (a) location on the map; (b) UAV multispectral image, R/G/B=Band 2/ Band 3/ Band 1 of the experiment field; (c) UAV image-generated digital surface model (DSM). 

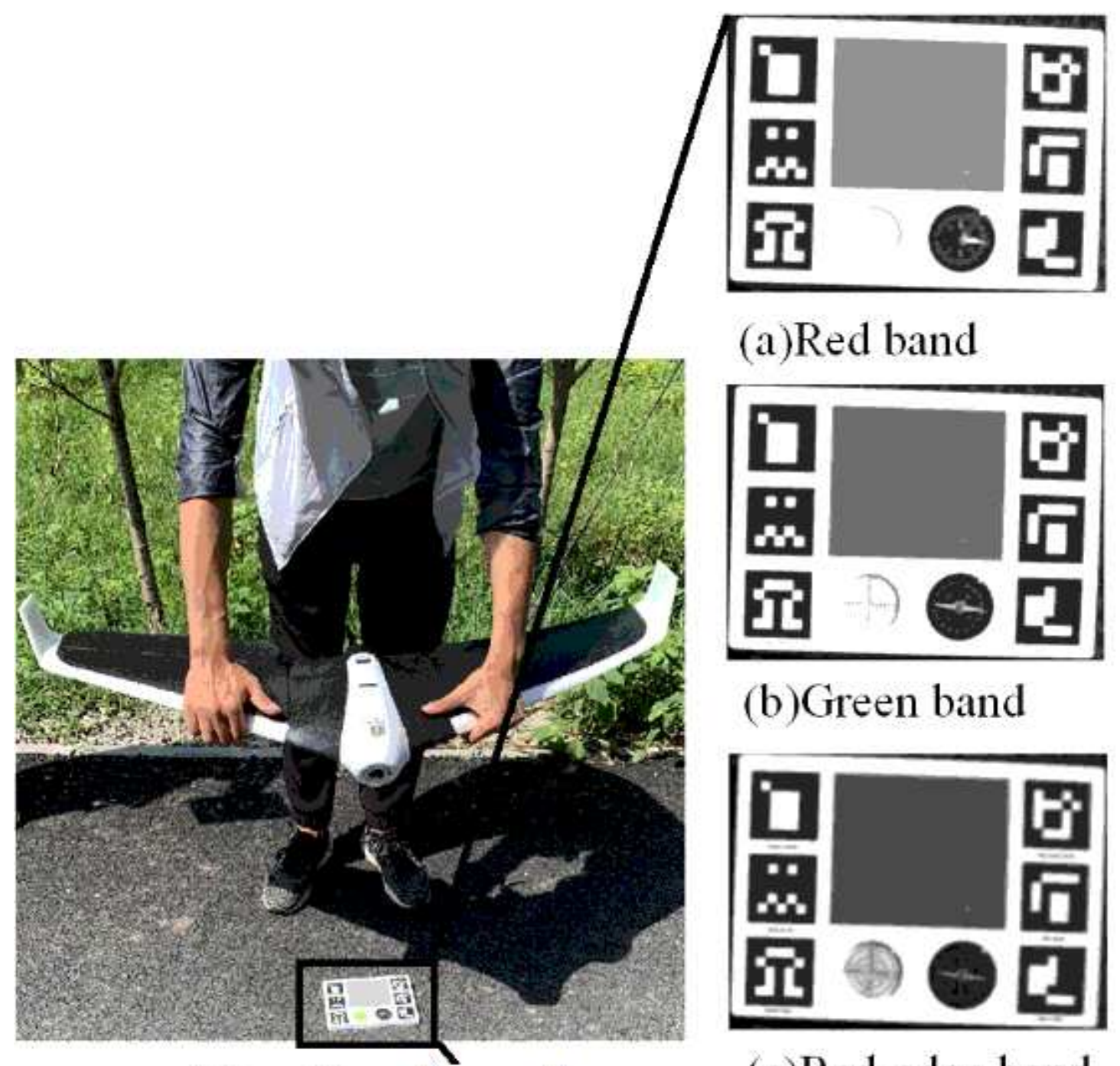

(b)Green band

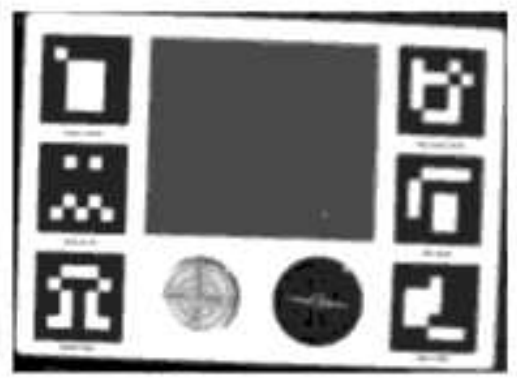

calibration board

(c)Red-edge band

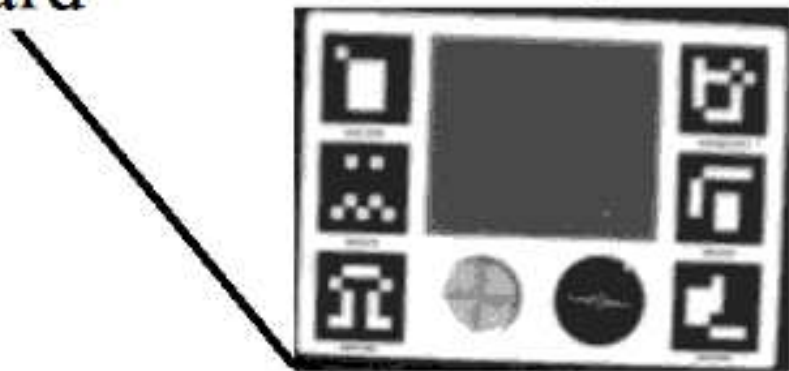

(d)NIR band

Figure 2

Shooting the calibration board on different bands. 


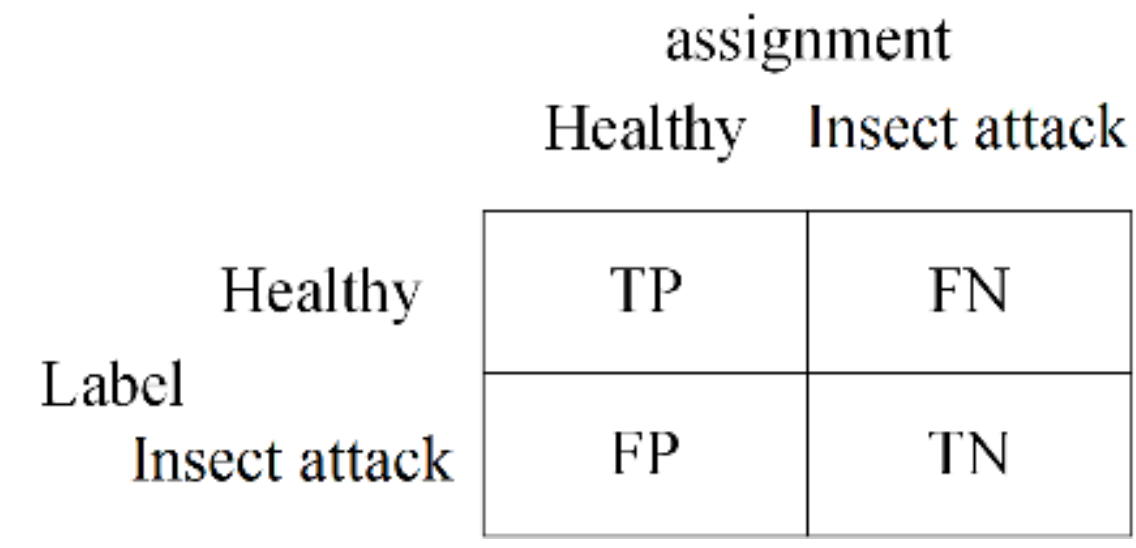

Figure 3

Confusion matrix of separation results.
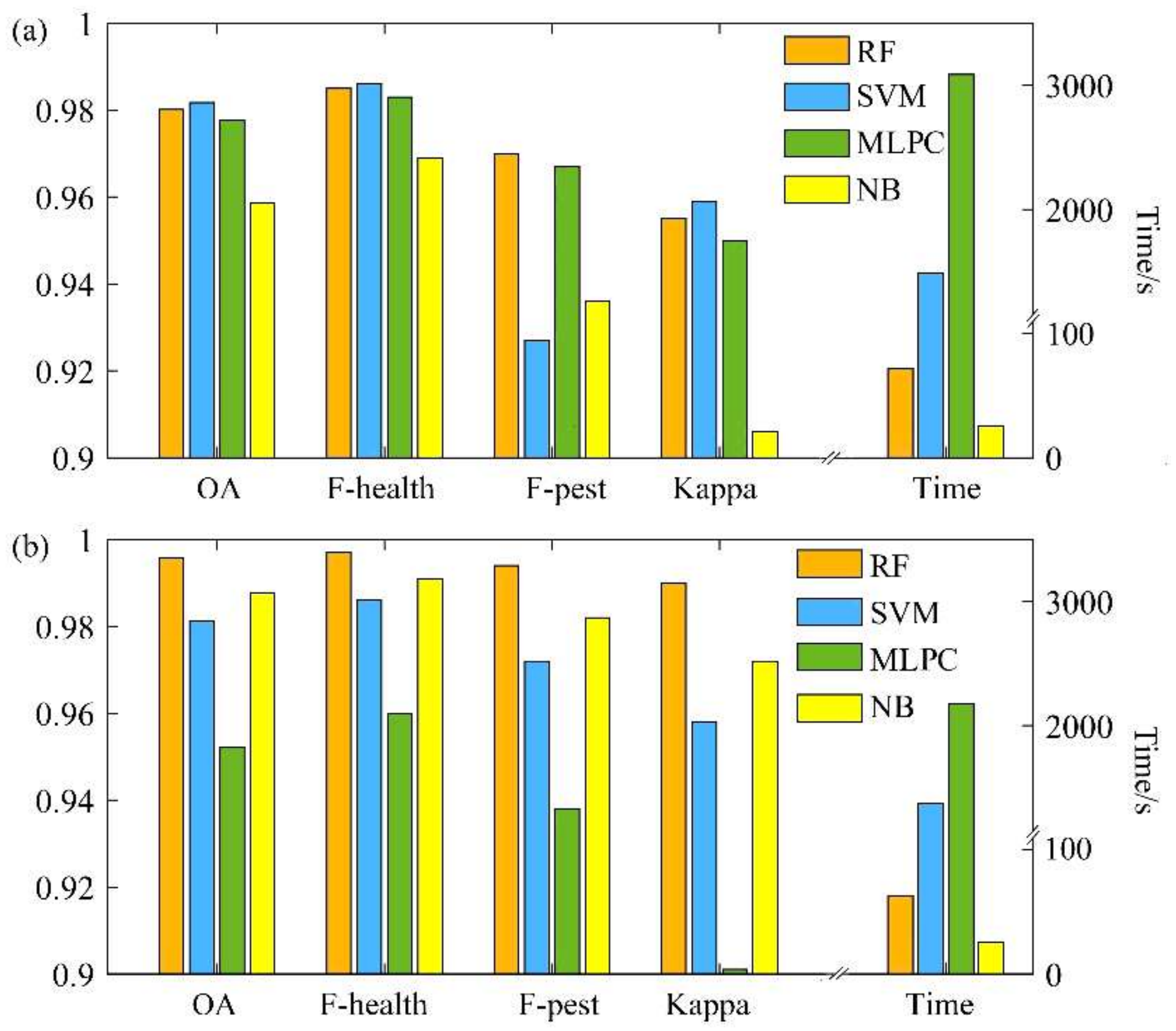


\section{Figure 4}

Results of the machine learning algorithms: (a) the multispectral images alone; (b) combined dataset (multispectral + DSM).

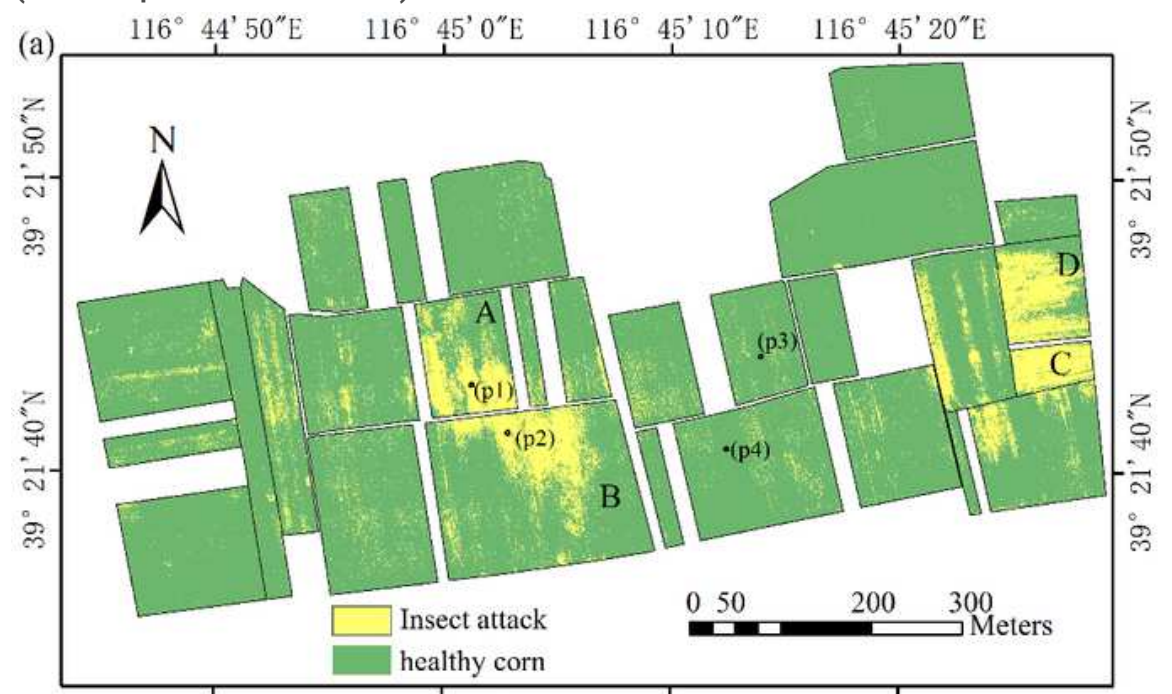

$116^{\circ} 44^{\prime} 50^{\prime \prime} \mathrm{E} \quad 116^{\circ} 45^{\prime} 0^{\prime \prime} \mathrm{E} \quad 116^{\circ} 45^{\prime} 10^{\prime \prime} \mathrm{E} \quad 116^{\circ} 45^{\prime} 20^{\prime \prime} \mathrm{E}$

(b)

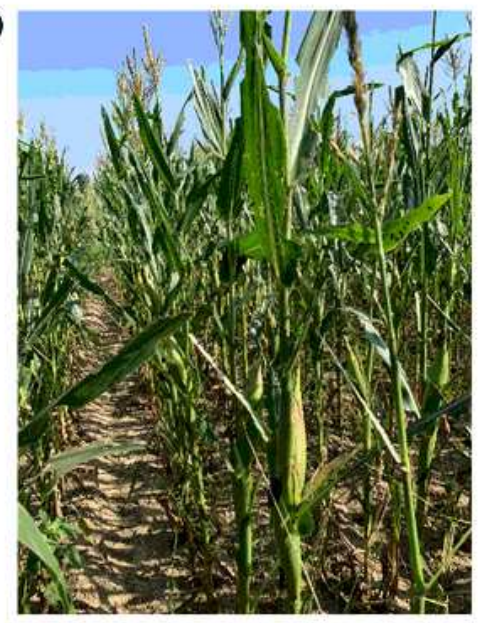

(d)

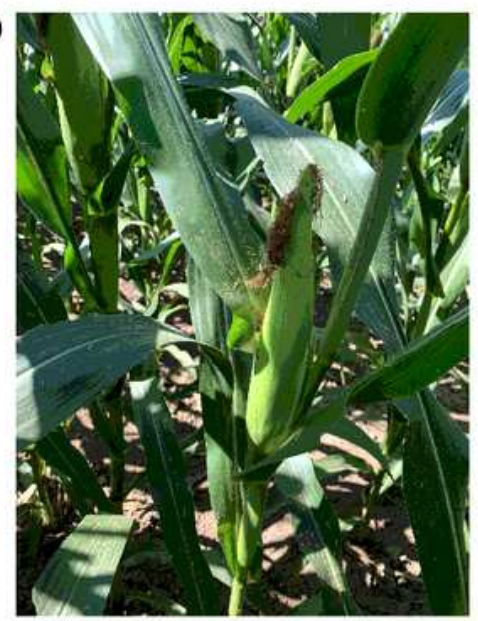

(c)

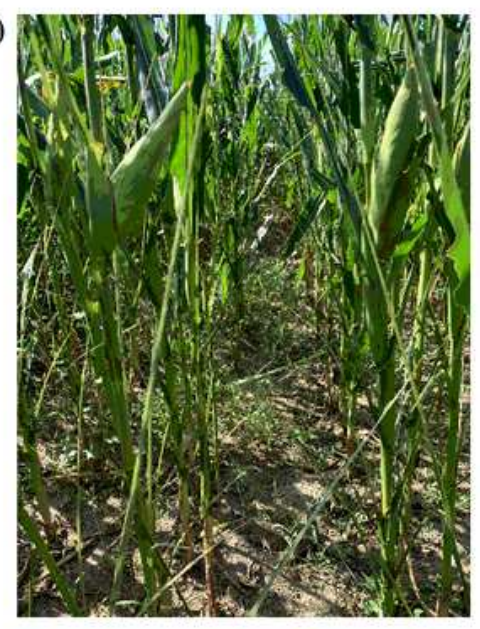

(e)

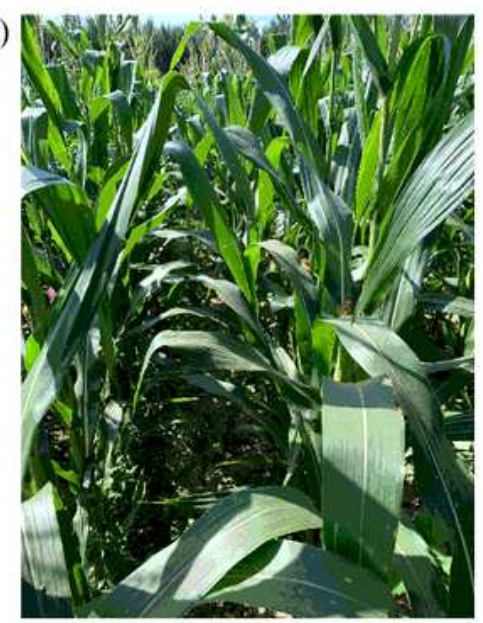

Figure 5 
Monitoring of the armyworm attack on summer corn by RF: (a) map of corn damaged by armyworm; (b) and (c) are the photos of points (p1) and (p2) in the area damaged by armyworm, respectively; (d) and (e) are the photos of points (p3) and (p4) in the healthy area, respectively.

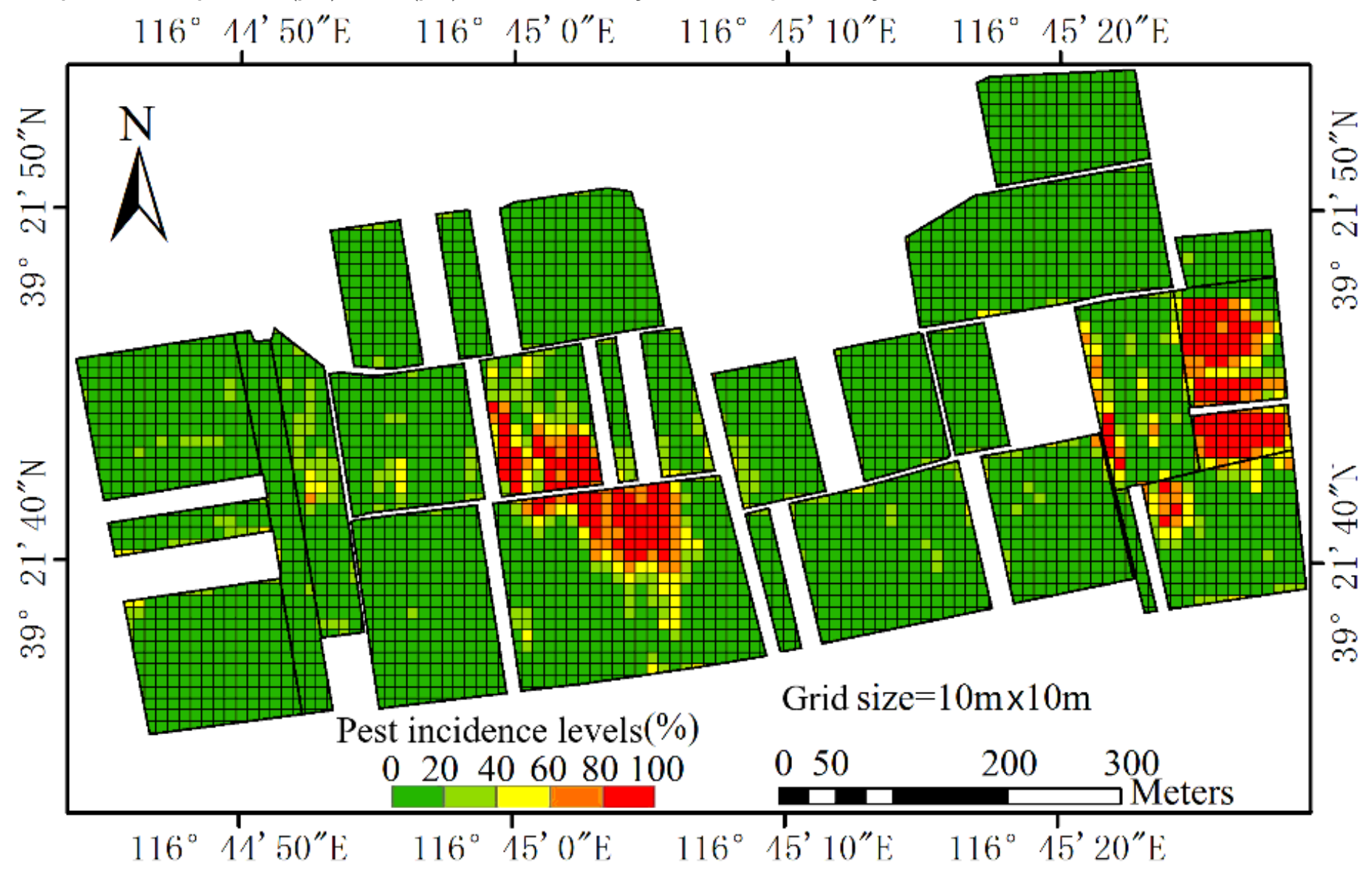

Figure 6

Pest incidence levels of corn in each $10 \times 10$ m grid. 


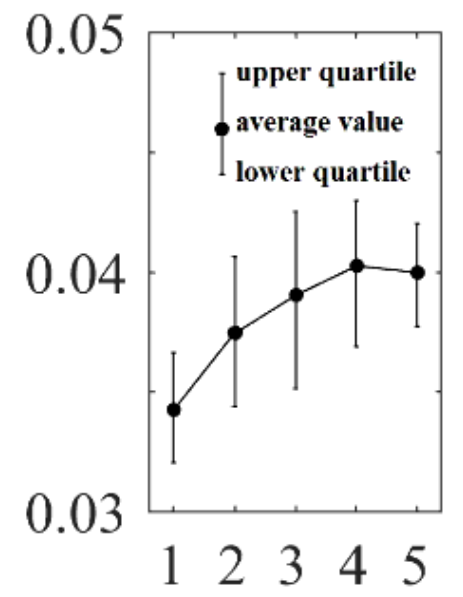

(a)

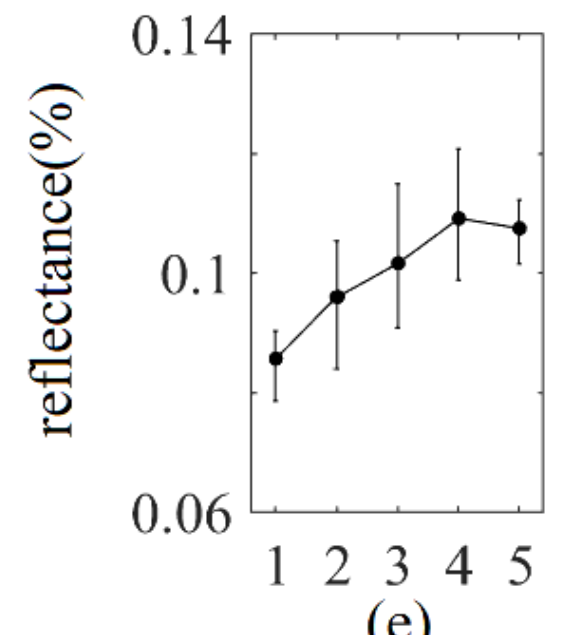

(e)

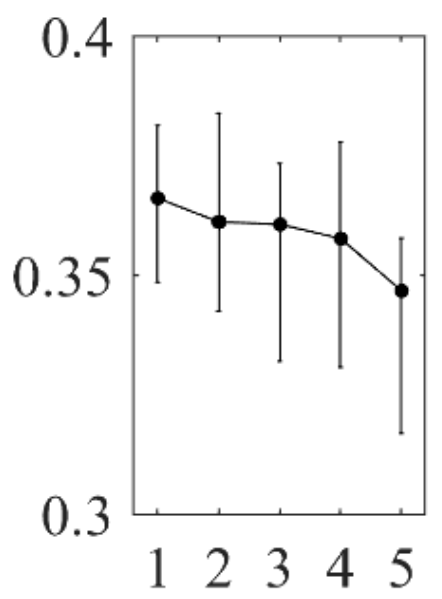

(i)

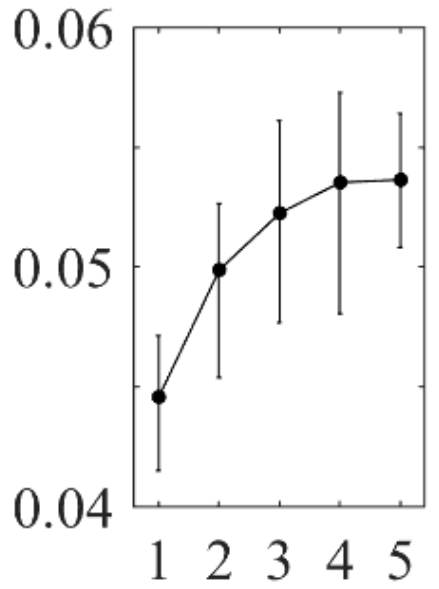

(b)

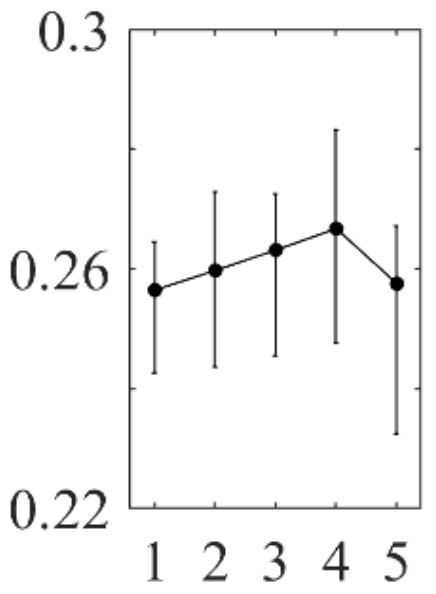

(f)

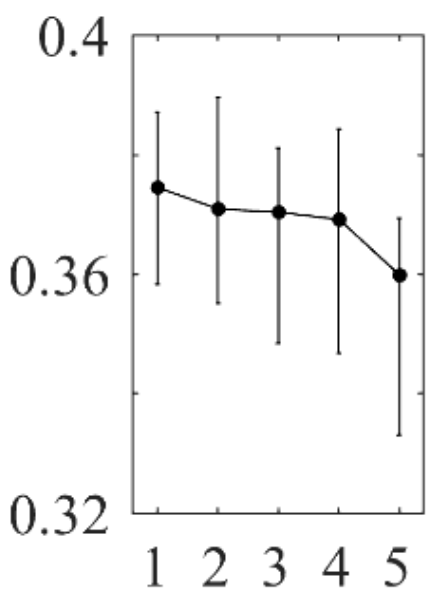

(j)

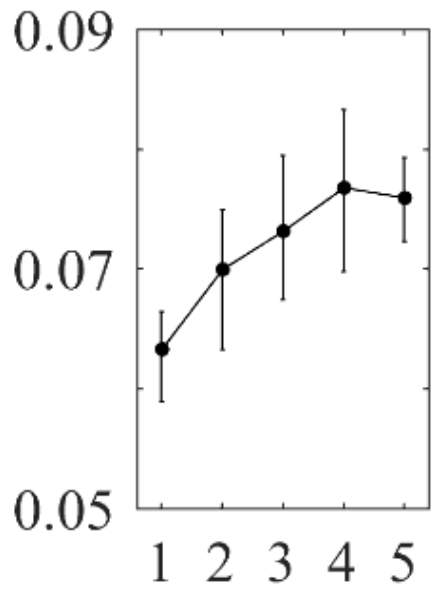

(c)

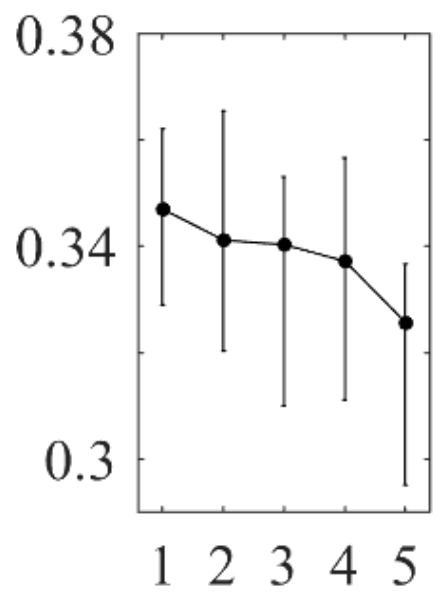

(g)

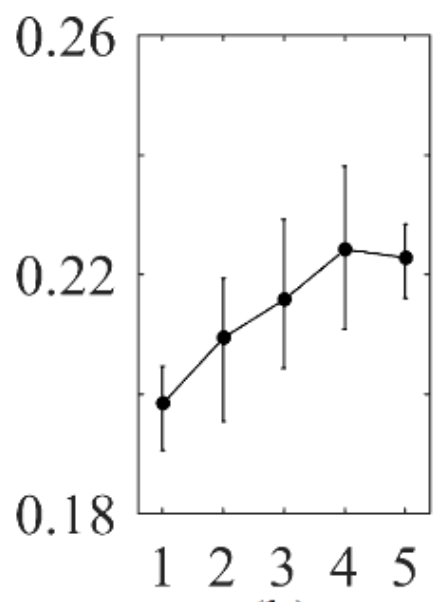

(k)

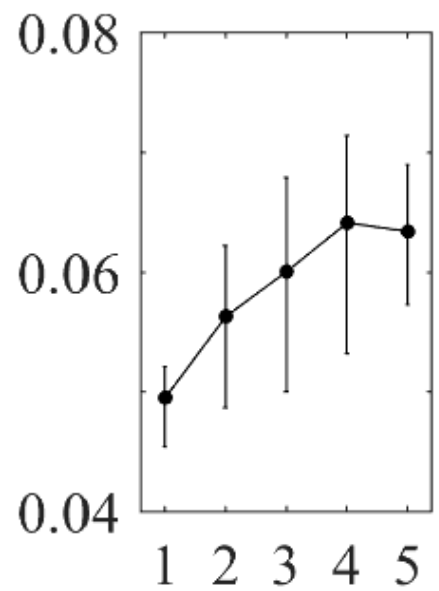

(d)

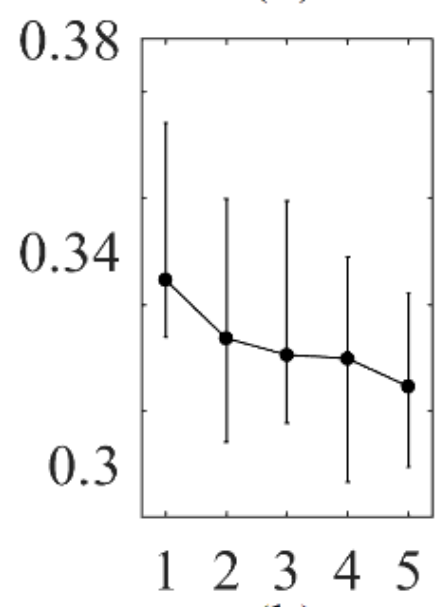

(h)

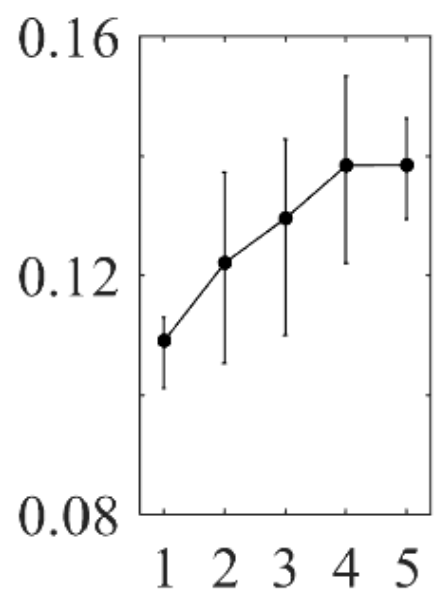

(1)

Figure 7

Spectral characteristics of different pest incidence levels in the Sentinel-2 image: the $x$-axis represents levels of armyworm incidence (\%) in corn (0-20, 20-40, 40-60, 60-80, 80-100). Plots (a)-(I) correspond to Band 1-Band 8, Band 8a, Band 9, Band 11 and Band 12 of Sentinel-2. 


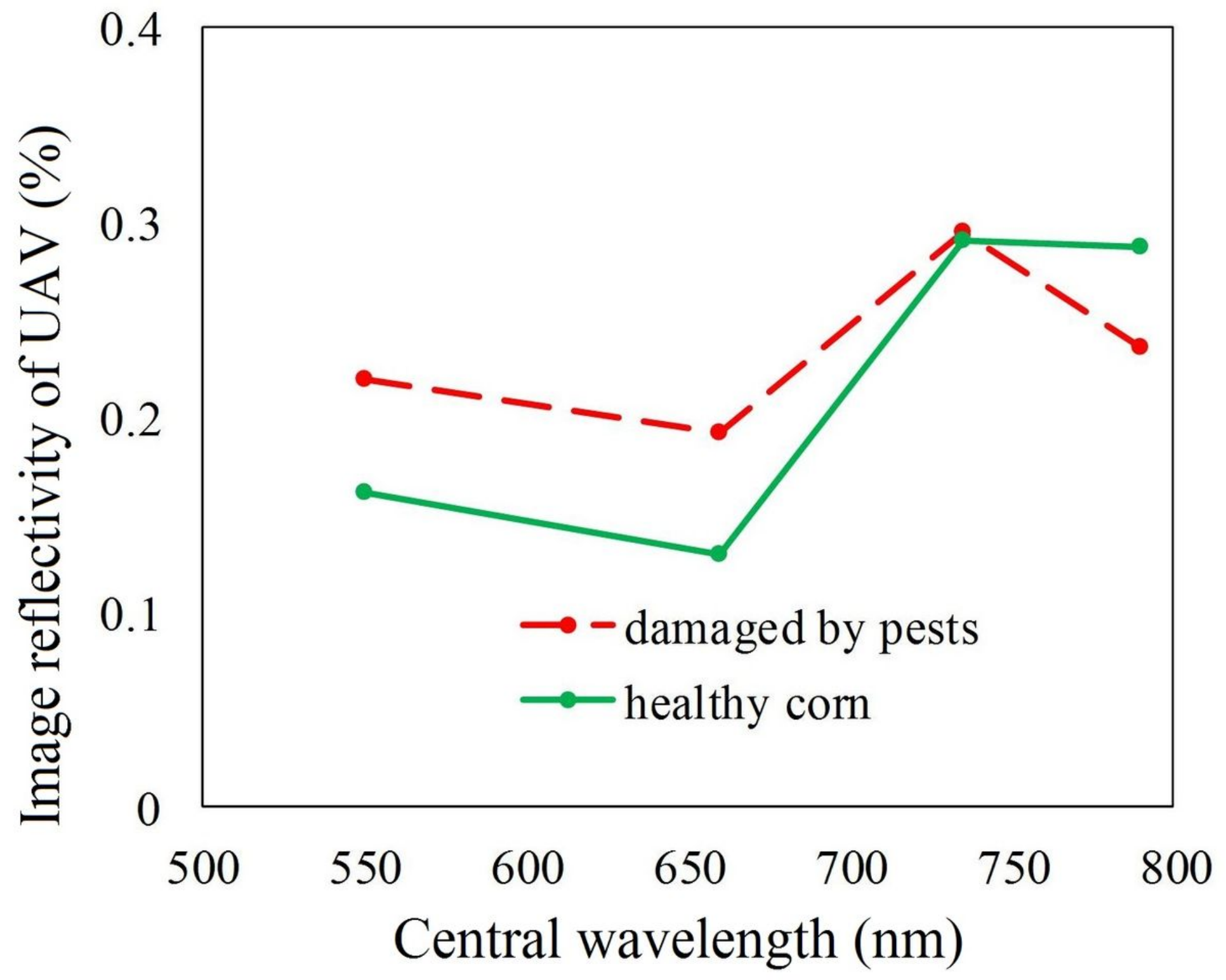

Figure 8

Canopy spectral response of UAV image in summer corn 


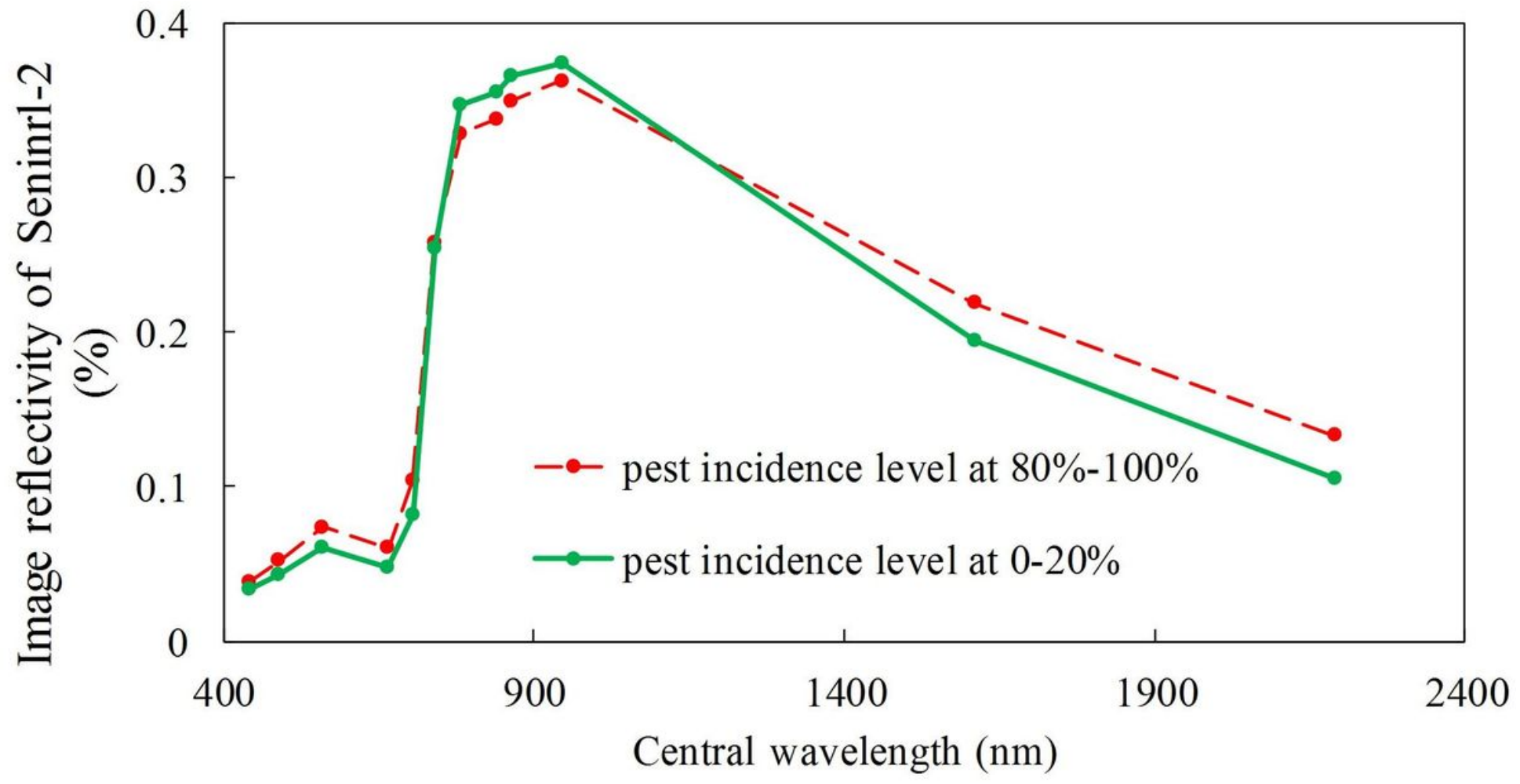

Figure 9

Canopy spectral response of Sentinel-2 image in summer corn 